\title{
Development of tropical cyclone wind field for simulation of storm surge/sea surface height using numerical ocean model
}

\author{
Yashvant Das $^{1,2} \cdot$ U. C. Mohanty ${ }^{1,3} \cdot$ Indu Jain ${ }^{1}$
}

Received: 8 December 2015/ Accepted: 10 December 2015/Published online: 28 December 2015

(C) Springer International Publishing Switzerland 2015

\begin{abstract}
Coupled ocean-atmospheric phenomenon such as tropical cyclones (TC's) is governed by geophysical fluid dynamics. TC associated strong wind stress transfer momentum energy to the ocean surface that acts as the prime mechanism in modulating the sea surface and in generating the storm surge. A primitive equation, Princeton ocean model (POM) with free surface, sigma (terrain-following) coordinates and realistic bottom topography is configured in Bay of Bengal (BoB) to simulate the storm surge/sea surface height ( $\mathrm{SSH}$ ) and surface currents during a super cyclone TC05B 1999. TC wind fields are developed by adopting a suitable formulation based on partial conservation of angular momentum. Modeled TC wind fields are superimposed with QuikSCAT Satellite/National Centre for Environmental Prediction (QSCAT/NCEP) blended ocean surface winds to drive the three-dimensional ocean model. Model simulated storm surge and SSH are compared with limited available surge estimates/observations and multi-satellite observed AVISO (Archive, Validation and Interpolation of Satellite Oceanography) SSH, respectively to evaluate its performance.
\end{abstract}

Keywords Tropical cyclone - Wind field · Storm surge · Sea surface height · Bay of Bengal

Yashvant Das

yashvantdas@rediffmail.com

1 CAS, Indian Institute of Technology, Hauz Khas, New Delhi 110016, India

2 Present Address: Research and Modelling Division, AIR Worldwide India (Verisk Analytics India Private Limited), Hyderabad 500081, India

3 Present Address: EOCS, Indian Institute of Technology, Bhubaneshwar 751013, India

\section{Introduction}

Convective activity such as tropical cyclones (TC's) is governed by geophysical fluid dynamics and is among the most devastating natural disasters known to mankind (Anthes 1982; Emanuel 2003; Okazaki et al. 2005). Strong wind, heavy rainfall and storm surge are the ways through which TC inflicts the damage on striking the coast in the preferred locations of the earth and impact the human society by destabilizing the socio-economic conditions and GDP of the nations (WMO 2010; Probst and Franchello 2012). The coupled ocean-atmospheric phenomenon, largescale atmospheric circulation, and cloud-scale processes associated with enhanced cumulus convection play a crucial role on the onset and development of the TC over the tropical ocean waters (Stan 2012). Apart from the pre-existing low level cyclonic disturbances as a pre-cursor, climatological conditions such as warm sea surface temperatures (SST's) above $26.5^{\circ} \mathrm{C}$ with a deep oceanic mixed layer, a conditionally unstable atmosphere, weak vertical wind shear, high relative vorticity, mid-troposphere high relative humidity and presence of moist convection provide the conducive environment for TC formation (Gray 1975; Frank 1977; Liang et al. 2014). Stan (2012) has argued that a region of organized convective activity is also necessary for the TC activity to occur. Also he indicated that the mesoscale organization of cumulus convection acts as a thermodynamic engine of the TC's. The large-scale environmental forcings (DeMaria et al. 1993) viz. easterly waves and tropical wave activity, including Rossby-gravity waves, equatorial Rossby waves, Madden Julian Oscillation (MJO) play an important role in the TC formations (Bessafi and Wheeler 2006; Frank and Roundy 2006). The favorable hydrographic conditions such as formation of stably stratified thick barrier layer in 
the upper ocean that acts as barrier to vertical mixing and entrainment cooling induced by TC's leading to an increase in heat fluxes from the ocean into the atmosphere play a dominant role for the enhanced TC activity over BoB during post monsoon seasons (Sprintall and Tomczak 1992; Sengupta et al. 2008; Balaguru et al. 2012). TC activity in $\mathrm{BoB}$ is strongly modulated by the tropical intraseasonal oscillation (ISO) (Yanase et al. 2010, 2012). The influence of coupled ocean-atmospheric phenomena such as El-Nino, El-Nino Modoki, MJO and Indian Ocean Dipole (IOD) etc. on cyclogenesis over NIO have been studied well (e.g. Girishkumar and Ravichandran 2012; Sumesh and Rameshkumar 2013).

$\mathrm{BoB}$ in NIO basin is one of the most potential breeding ground for the TC formation. There are two TC seasons in $\mathrm{BoB}$, one the pre-monsoon (April-May) and other the post monsoon (October-December). The annual cycle of BoB TC's is characterized by bimodal structure. TC's in the BoB have distinct features and exhibit strong differences from those in other basins viz. Pacific (Western North Pacific, Western South Pacific), North Atlantic and South Indian Ocean ( $\mathrm{Li}$ et al. 2013; Wang et al. 2013). The frequency of occurrence of $\mathrm{TC}$ in $\mathrm{BoB}$ is relatively higher during post-monsoon periods; however, there is a marked seasonal variation in their places of genesis, tracks and intensities (Mohanty et al. 2004; Wang et al. 2013). Air-sea feedbacks strongly affect the location of cyclogenesis, as evidenced in Jullien et al. (2014). The characteristics of ocean basins and other ocean-atmospheric factors also determine the duration, frequency and intensity of the TC's. About 80-90 TC's form annually in the world ocean basins and BoB's share comes out to be $\sim 5-6 \%$ of the total world ocean waters (Gray 1979). The average speeds of movement of the BoB TC's are about $6.25 \mathrm{~m} / \mathrm{s}$ (Crutcher and Quayle 1974), with shorter average life span of 2-3 days (due to their short stay over ocean) against the world average of $\sim 6$ days (Riehl 1979). TC's originating in $\mathrm{BoB}$ move primarily along northwesterly and easterly directions. Recurvatures of some cyclonic disturbances from an initial northwesterly direction to a northerly direction and finally towards northeasterly direction is the common feature (IMD 1996). Chan and Gray (1982) and Elsberry et al. (1987) have evidenced that large-scale environmental steering flows and beta effect propagation govern the motion of the TC's.

The $\mathrm{BoB}$ is the region where the deadliest TC's occurred and the BoB-rim countries such as India, Bangladesh and Myanmar mostly suffer due to strong winds, heavy rains and record flooding (surges) (Li et al. 2013). Since, BoB is a semi-enclosed, funnel shaped Bay, so most of the TC's that form make landfall, giving BoB TC's a disproportionately high societal importance relative to their small total number (Balaguru et al. 2014). Moreover, the shallow bathymetry, coastal orientation and densely populated coastal inhabitant pose an additional threat to high surge height resulting in significant loss of lives and property (McBride 1995; Webster 2008; Islam and Peterson 2009; McPhaden et al. 2009). The highest recorded storm surge $(\sim 12.5 \mathrm{~m})$ was associated with the Backergunj cyclone that was originated in BoB in 1876 and struck near Meghna estuary in Bangladesh. In the historical cyclone records, seven of the top ten deadliest cyclones have formed in the $\mathrm{BoB}$ and the most recent example is cyclone Nargis (May 2008) in Myanmar (Webster 2008; Lin et al. 2009; McPhaden et al. 2009; Yanase et al. 2010). TC Sidr (November 2007) which was a Category 4 storm in SaffirSimpson Tropical Cyclone Scale (SSTCS) brought about a devastating coastal flooding with $\sim 5.8 \mathrm{~m}$ of surge height and $\sim 1.7$ billion (USD) of damage in Bangladesh. Phailin (October 2013) was a Category 5 storm in SSTCS and was one of the most intense systems ever observed in the BoB with winds of up to $250 \mathrm{~km} / \mathrm{h}$. Heavy rainfall and flooding exacerbated by a storm surge caused millions of worth of economic losses in India. Vulnerability to storm surges is not uniform along Indian coasts. According to the vulnerability Atlas of BMTPC (2006), the probable maximum surge height (PMSS) varies from $\sim 12.5 \mathrm{~m}$ (highest) in West Bengal coast in north to $\sim 8.4 \mathrm{~m}$ at Nagapattinam, Tamilnadu in south along the east coast of India. The west coastal states are comparatively less vulnerable due to storm surges. Along the west coast, the PMSS varies from $\sim 2 \mathrm{~m}$ near Thiruvananthapuram to $\sim 5 \mathrm{~m}$ near the Gulf of Khambat in the Saurashtra region of Gujarat (CRRI 2013). The impact of the storm in generating the surface currents, modulating the SSH and giving rise to the storm surge is well investigated (Wang et al. 2012; Wang and Han 2014). Strom induced SSH changes and their anomalies (positive and negative) have the strong bearing in dynamic and thermodynamic characteristics of the ocean and in modulating the air-sea interaction processes in different seasons and scales. Variations in SSH provide the information of the subsurface ocean and air-sea interaction parameters like thermocline and upper ocean heat content. Propagation of planetary Kelvin and Rossby waves can be observed using SSH anomaly (Chelton and Schlax 1996; Polito and Cornilion 1997). SSH is an indicator of the vertically integrated density changes in the entire water column (Gera et al. 2013). SSH is also used as a proxy of the upper ocean heat content. Surface current and SSH variations have been studied extensively for BoB, South China Sea (SCS), Gulf of Mexico (GOM) and Gulf of Thailand (GOT) (Rao et al. 1993; Chu et al. 2000; Oey et al. 2005; Aschariyaphotha et al. 2013) and other oceanic basins.

Pioneering studies on TC wind and storm surge resulting from historical, hypothetical, or predicted TC's using SLOSH (Sea, Lake, and Overland Surges from Hurricanes) 
model for different oceanic basins have been documented well (Jelesnianski et al. 1992; Glahn et al. 2009; Dube et al. 2010). ADCIRC (Advance CIRCulation) numerical model was applied along the GOM, Caribbean Sea and BoB (Blain et al. 1994; Rao et al. 2012). SLOSH and ADCIRC models along with parametric wind field models were extensively used for storm surge studies by Dietsche et al. 2007; Cardone and Cox 2009; Melton et al. 2009; Bunya et al. 2010; Dietrich et al. 2010 and Niedoroda et al. 2010 in different oceanic basins. POM was implemented by Xia et al. (2008) to simulate the storm induced surge, inundation, and coastal circulation at the Cape Fear River estuary and adjacent Long Bay. The fully nonlinear Finite Volume Coastal Ocean Model (FVCOM) with a high-resolution unstructured mesh was implemented to study the storm surge due to Hurricane Ike along the Texas-Louisiana coast (Rego and Li 2010). You et al. (2010) compared the storm surge outputted by POM and Regional Ocean Modeling System (ROMS) by taking the cases of three typhoons that struck Korea in 2007. Several authors including Higaki and Hayashibara (2008) and Higaki et al. (2009) have described the JMA (Japan Meteorological Agency) storm surge model which includes the parametric wind model (Fujita 1952) and non-hydrostatic model (Saito et al. 2006). A good number of storm surge studies have been documented for BoB (NIO) basin using monograms, empirical, theoretical and numerical methods (e.g. Ali 1979; Lwin 1980; Das et al. 1983; Ghosh 1985; John et al. 1983; Murty et al. 1986; Flather 1994; Dube et al. 2000, 2004; Rao et al. 2012; Jain et al. 2010). Detailed reviews on numerical studies on storm surges over BoB have been presented by Murty et al. (1986) and more recently by Shaji et al. (2014). They have indicated that in most cases the numerical storm surge models were forced with the reconstructed wind and pressure fields, adopting the methodologies based on Holland (1980) and Jelesnianski et al. (1992) by utilizing the storm track data from JTWC and IMD.

The $\mathrm{BoB}$ is one of the largest marginal seas of the Indian Ocean, extending across both tropical and subtropical zones and encompassing a surface area of $2.2 \times 10^{6} \mathrm{~km}^{2}$. It is bordered by Sri Lanka and India to the west, Bangladesh to the north, and Myanmar and the northern part of the Malay Peninsula to the east (Fig. 1). The Bay is about $1600 \mathrm{~km}$ wide, with an average depth of more than $2600 \mathrm{~m}$ (http://www.britannica.com/EBchecked/topic/60740/Bay-ofBengal.). The wind circulation in the $\mathrm{BoB}$ is governed by the summer and winter monsoons respectively and accordingly magnitude changes from maximum to minimum. The monsoons play a distinct role in generating and influencing the north-south flowing coastal currents, the cyclonic and anticyclonic eddies and the BoB gyres (Shetye et al. 1993; Shetye et al. 1996; Vinayachandran et al.

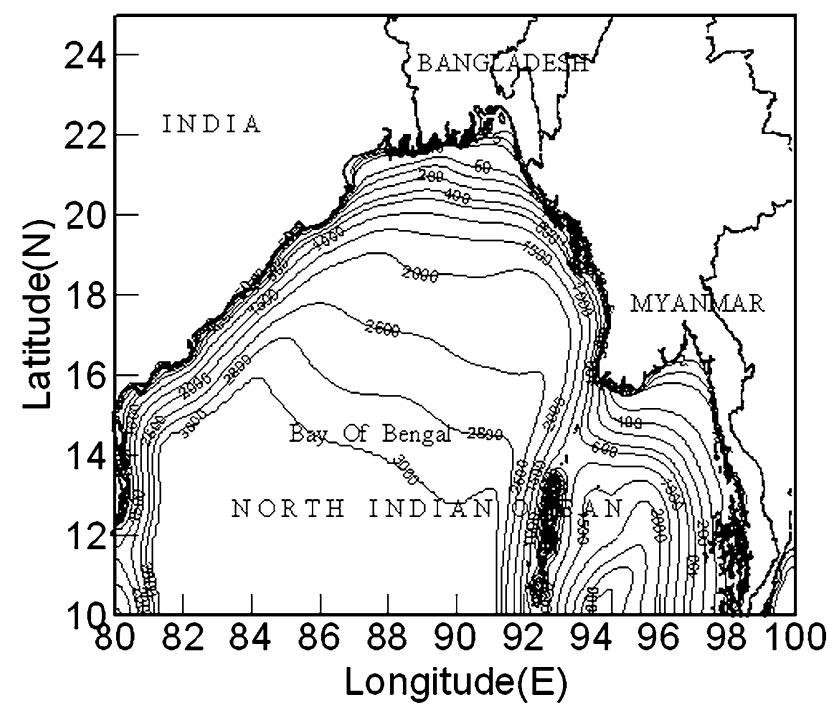

Fig. 1 Map of the study domain representing the bathymetric contours (meters) of Bay of Bengal (North Indian Ocean) with boundary of bordering countries

1996; Sil and Chakraborty 2011). Ali et al. (2007) have evidenced that, TC's intensify (dissipate) after traveling over anticyclonic (cyclonic) eddies. Murty et al. (1998) have noted the persistence of Warm Pool $\left(28.0^{\circ} \mathrm{C}\right)$ from April to October in the BoB. The warming of the central basin caused by trapping of Kelvin waves in the central Bay for many months creates conducive environment for cyclogenesis (Saheb et al. 2009). Sadhuram et al. (2004) have reported that the climatological average value of tropical cyclone heat potential (TCHP) for the Bay is $\sim 60 \mathrm{~kJ} / \mathrm{cm}^{2}$ and is considered as the threshold values for cyclogenesis.

Keeping in view the devastating effect of the storm surge and importance of SSH and current variation in ocean-atmospheric studies, a numerical ocean model has been implemented in $\mathrm{BoB}$ to simulate the storm surges, SSH and surface currents due to a super cyclonic storm (TC05B) of October 1999. Since, quantitatively, neither the satellite-retrieved nor numerical model/reanalysis winds able to represent realistically the observed magnitude of TC's, although the general circulation patterns are captured (Wang and Han 2014). So, a TC wind field model based on the formulation of Carr and Elsberry (1997) is adopted for developing cyclonic winds. Generated wind fields are then superimposed with the QuikSCAT Satellite/National Centre for Environmental Prediction (QSCAT/NCEP) blended ocean surface winds to represent the realistic cyclonic winds to force the ocean model for the storm surge, SSH and surface current simulation. Also, it is evident that an ocean condition is closely associated with cyclogenesis. This close association has spawned considerable scientific interest in how the ocean influence and responds to TC's. 
Moreover, studies on storm surge/SSH is of utmost importance in the era of changing global climate with varying storm characteristics (intensity and frequency) and shifting genesis locations of the world oceanic basins for the coastal risk monitoring and assessment. Thus, BoB with its unique physiographic, climatological and physicochemical characteristics was chosen to investigate the storm surge, SSH and surface currents due to a super cyclonic storm using the numerical ocean model (POM).

The outline of the paper is as follows. Introduction is given in Sect. 1. Section 2 describes the life history of a super cyclone (TC05B) 1999 over the BoB. Section 3 dictates about the modeling TC wind fields and the QSCAT/NCEP blended ocean surface wind data. Section 4 describes the POM model, study domain, initial and boundary conditions and the experimental setup. Section 5 describes the results of the numerical simulation and Sect. 6 gives the conclusions.

\section{Tropical cyclone (TC05B) 1999}

TC05B 1999 (also known as Orissa super cyclone) was one of the most disastrous and significant TC's on record to affect India. It was a Category 5 cyclone in SSTCS. It made landfall near Paradip (Orissa), India at around 0600 UTC on 29 October, 1999 (JTWC 1999; IMD). Just prior to landfall, it had attained the minimum central pressure of $912 \mathrm{mb}$ as reported by IMD. It impounded very heavy rainfall and flooding exacerbated by the storm surges. It claimed approximately 10000 lives and left millions of people homeless and without food (International Federation of Red Cross and Red Crescent Societies 2001). The damage across fourteen districts in India resulted from the storm was approximately $\$ 4.5$ billion (1999 USD) (Swiss Re 2002).

The system (TC05B) is chosen to study the storm surge/ SSH as a case study due to its super cyclonic status and significant impact over ocean and eastern maritime states of Indian subcontinent.

\section{Tropical cyclone history}

TC05B developed from a disturbance that originated in the SCS on 23 October at 0200 UTC and tracked through the GOT and across the Malay Peninsula before developing in the Andaman Sea. JTWC issued a Tropical Cyclone Forecast Analysis (TCFA) on 23 October at 0200 UTC and continued monitoring the system. Subsequently, it moved into the Andaman Sea on 24 October, where the convection began to consolidate to form depression (JTWC 1999). $\mathrm{TC} 05 \mathrm{~B}$, first entered the $\mathrm{BoB}$ late on 25 October as a tropical depression $(12.5 \mathrm{~m} / \mathrm{s}$, i.e., 25 knots, 1 knots $=0.5 \mathrm{~m} / \mathrm{s}$ ) centered at $12.7^{\circ} \mathrm{N}, 96.9^{\circ} \mathrm{E}$ at $1200 \mathrm{UTC}$ as suggested by wind analyses. The first warning was issued on 26 October at 0300 UTC as the depression developed into a cyclonic storm $(17.5 \mathrm{~m} / \mathrm{s})$ and lay centered at $14.8^{\circ} \mathrm{N}, 94^{\circ} \mathrm{E}$ southeast of Orissa, India. The system then tracked northwestward (at an average forward speed of $\sim 4.5 \mathrm{~m} / \mathrm{s}$ ) and intensified across the BoB under the steering influence of the subtropical ridge to the north and had taken the position $17.5^{\circ} \mathrm{N}, 90.6^{\circ} \mathrm{E}$ by $1200 \mathrm{UTC}$ on 27 October. The system attained the peak intensity of $70 \mathrm{~m} / \mathrm{s}$ on 28 October at $1800 \mathrm{UTC}$, centered at $19.1^{\circ} \mathrm{N}$, $87.2^{\circ} \mathrm{E}$. The intensification was at a greater than climatological rate. It made landfall $11 \mathrm{~h}$ later at about $65 \mathrm{~km}$ south-southeast of Cuttack and $55 \mathrm{~km}$ southeast of Bhubaneswar, India with maximum sustained winds of $\sim 67.5 \mathrm{~m} / \mathrm{s}$. Figure 2 illustrates the satellite image (EUMETSAT, METEOSAT by NOAA) of the TC05B at landfall. The eye of the system is clearly visible crossing the coastline and spiraling bands of clouds around the eyewall region is evident from the image. Subsequently, the system maintained $50 \mathrm{~m} / \mathrm{s}$ intensity for $12 \mathrm{~h}$ as it dumped torrential rains and battered the coastal areas. The system remained practically stationary inland for about a day and interacted with topography which helped in enhanced rainfall. The system then slowly turned southward and moved back over to the $\mathrm{BoB}$ as a $20 \mathrm{~m} / \mathrm{s}$ tropical cyclone. Later, it continued to drift southward and dissipated over ocean water under the unfavorable ocean-atmospheric conditions (JTWC 1999). Figure 3 shows the track of the storm, tracked along the northwesterly direction as provided by JTWC.

The super cyclone brought extensive inundation from the storm surge in the low-lying areas and impacted up to

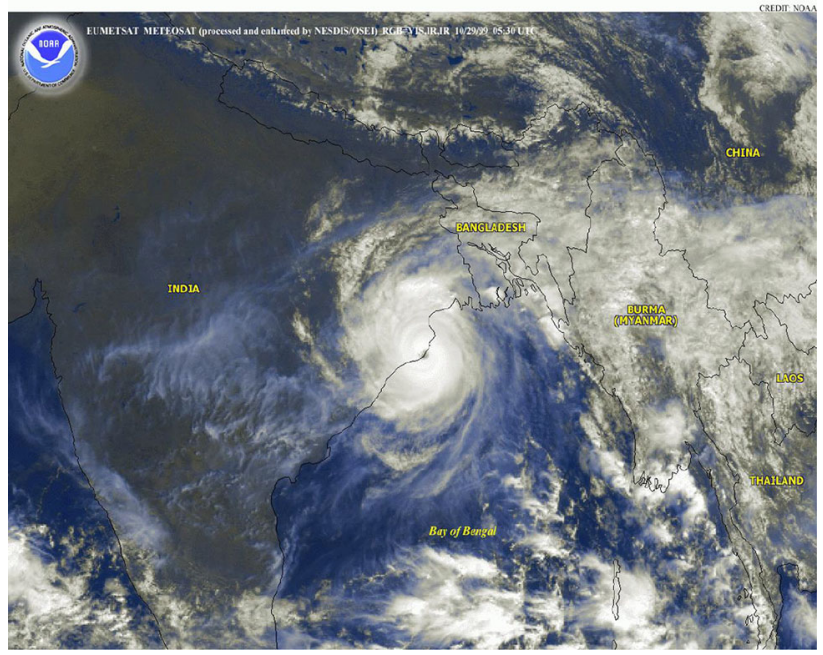

Fig. 2 EUMETSAT METEOSAT satellite imagery of TC05B 1999 on $29 / 10 / 1999$ at 05.30 UTC (Source: NOAA) 


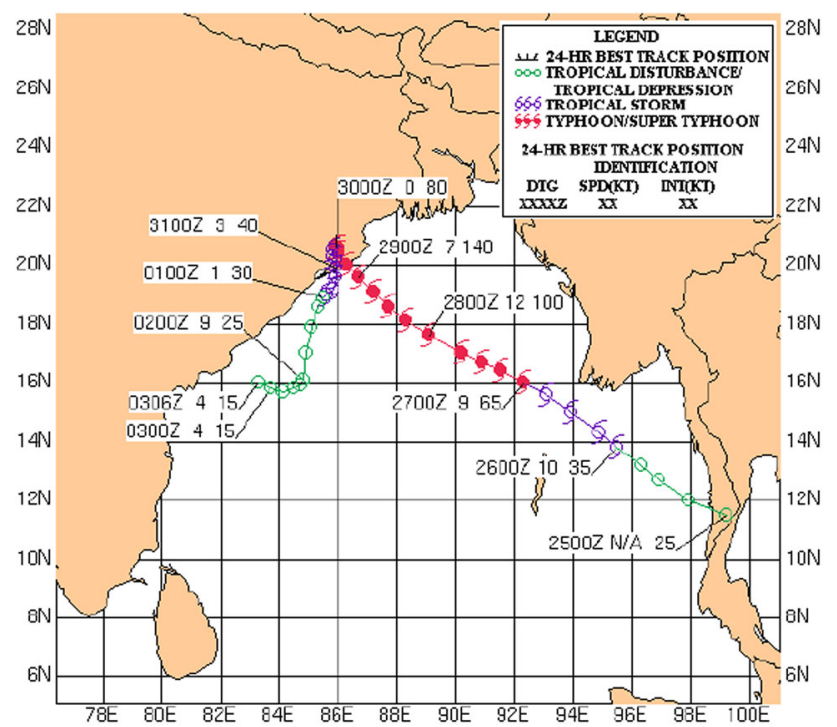

Fig. 3 Track of TC05B, 1999 with track characteristics (Source: JTWC)

$\sim 35 \mathrm{~km}$ inland. The maximum coastal flooding occurred in the right -forward quadrant of the system during the landfall. The coastal area became more vulnerable because of the shallow continental shelf and the combined effect of the non-linear wave-tide-surge interaction. A detail characteristic of this system is described by Kalsi (2006).

\section{Tropical cyclonic wind model (TCWM)}

TC wind fields are usually modeled using parametric as well as numerical dynamical models for various applications in engineering and scientific fields. It is evidenced that the satellite-retrieved winds, high resolution atmospheric reanalysis and Numerical Weather Prediction (NWP) products have difficulties realistically representing TC's, especially their intensity and track (Schenkel and Hart 2012). However, recent improvement and advancement in modeling capabilities (such as in GFDL, HWRF and ECMWRF) could predict and produce adequately the pressure and wind fields of cyclones that could be inputted to storm surge models (Miller 2010; Probst and Franchello 2012), though running such models require high computing resources and cost. Therefore, it necessitates modelling of TC winds using cost effective and limited parameter driven simple parameterized models to overcome the significant underestimation of TC's high wind situation (Wang et al. 2012). The parametric model offers an attractive alternative because the model improves execution-time-costs and preserves most of the validity of the numerical results (Wood and White 2011). Though many investigators prefer the high resolution numerical model over the parametric model; the parametric model still provides an economical and equally good alternative for estimating vortex wind fields (or profiles) for different applications (Wood and White 2011). TC wind field models have been described in detail by Holland (1980); Jelesnianski et al. (1992); Carr and Elsberry (1997); Willoughby et al. (2006); Holland et al. (2010). These models are widely used by scientific community to approximate the one-or two-dimensional wind structure within a cyclonic vortex for driving the numerical ocean models for storm surge, wave and current simulations. In this study TC wind profile model as described by Carr and Elsberry (1997) is adopted in generating the cyclonic wind fields. Veneziano (1998); Chu et al. (2000); Yin et al. (2007) and Das et al. (2014) have used this model in generating the wind fields to drive the numerical ocean model. Storm parameters available for the system are used from the best track data sources as model input for wind field generation.

\section{Storm data}

Storm information's utilized are from the JTWC (U.S. Navy Joint Typhoon Warning Centre at Guam) best track archives. JTWC is the prime source in deriving the input parameters. JTWC tracks provide the 6-hourly information's on the latitude/longitude of the eye locations with date and time, the maximum sustained winds $\left(V_{\text {max }}\right)$, central pressure $(C p)$, etc. (Table 1$)$. The India Meteorological Department (IMD) archived best track data are also obtained from Regional Specialized Meteorological Centre (RSMC) of the Northern Hemisphere Analysis Centre (NHAC), Head Quartered (HQ) at New Delhi. RSMC is recognized by the World Meteorological Organization (WMO). IMD track information's containing the parameter viz. time, location (latitude/longitude) of the eye, $V_{\text {max }}$, $C p$, etc. are available in 3- and 6-hourly time intervals in digitized format and e-Atlas format. Data from RSMC (IMD) are utilized for comparison purposes with the JTWC data for further analysis, since data sets provided by different meteorological agencies are not the same due to their different averaging time, sampling rates and satellite based algorithms in deriving the storm parameters.

In most formulations, the dominant model input parameters are TC track positions (latitude/longitude), intensity $\left(C p, V_{\max }\right)$, the radius of maximum winds $\left(R_{m}\right)$, and a size $\left(R_{o}\right)$ indicator (Demaria et al. 1992). The $R_{o}$ is often inferred from position and the value of the last closed isobar around the storm or the distance to a specific wind speed expected in the absence of the TC (Demaria et al. 1992). Some of the storm information's viz. $R_{m}, R_{o}$ and translational velocity etc. are not available in each TC basin (Knaff et al. 2010). Several methods have been 
Table 1 Storm track data for TC05B 1999 (JTWC)

\begin{tabular}{|c|c|c|c|c|c|c|}
\hline Date/year & $\begin{array}{l}\text { Time } \\
\text { UTC }\end{array}$ & $\begin{array}{l}\text { Lat. } \\
\text { (Deg.) }\end{array}$ & $\begin{array}{l}\text { Lon. } \\
\text { (Deg.) }\end{array}$ & $\begin{array}{l}\text { Wind speed } \\
\text { (Knots) }\end{array}$ & $\begin{array}{l}\mathrm{Cp} \\
(\mathrm{mb})\end{array}$ & Status \\
\hline $10 / 25 / 1999$ & 0000 & 11.50 & 99.20 & 25 & - & Tropical depression \\
\hline $10 / 25 / 1999$ & 0600 & 12.00 & 97.90 & 25 & - & Tropical depression \\
\hline $10 / 25 / 1999$ & 1200 & 12.70 & 96.90 & 25 & - & Tropical depression \\
\hline $10 / 25 / 1999$ & 1800 & 13.20 & 96.30 & 25 & - & Tropical depression \\
\hline $10 / 26 / 1999$ & 0000 & 13.80 & 95.50 & 35 & - & Tropical storm \\
\hline $10 / 26 / 1999$ & 0600 & 14.30 & 94.90 & 35 & - & Tropical storm \\
\hline $10 / 26 / 1999$ & 1200 & 15.00 & 93.90 & 45 & - & Tropical storm \\
\hline $10 / 26 / 1999$ & 1800 & 15.60 & 93.10 & 50 & - & Tropical storm \\
\hline $10 / 27 / 1999$ & 0000 & 16.00 & 92.30 & 65 & - & Cyclone-1 \\
\hline $10 / 27 / 1999$ & 0600 & 16.40 & 91.50 & 75 & - & Cyclone-1 \\
\hline $10 / 27 / 1999$ & 1200 & 16.70 & 90.90 & 90 & - & Cyclone-2 \\
\hline $10 / 27 / 1999$ & 1800 & 17.00 & 90.20 & 95 & - & Cyclone-2 \\
\hline $10 / 28 / 1999$ & 0000 & 17.60 & 89.10 & 100 & - & Cyclone-3 \\
\hline $10 / 28 / 1999$ & 0600 & 18.10 & 88.30 & 115 & - & Cyclone-4 \\
\hline $10 / 28 / 1999$ & 1200 & 18.60 & 87.70 & 135 & - & Cyclone-4 \\
\hline $10 / 28 / 1999$ & 1800 & 19.10 & 87.20 & 140 & - & Cyclone-5 \\
\hline $10 / 29 / 1999$ & 0000 & 19.60 & 86.70 & 140 & - & Cyclone-5 \\
\hline $10 / 29 / 1999$ & 0600 & 20.00 & 86.30 & 135 & - & Cyclone-4 \\
\hline $10 / 29 / 1999$ & 1200 & 20.40 & 86.00 & 115 & - & Cyclone-4 \\
\hline $10 / 29 / 1999$ & 1800 & 20.60 & 86.00 & 100 & - & Cyclone-3 \\
\hline $10 / 30 / 1999$ & 0000 & 20.60 & 85.90 & 80 & - & Cyclone-1 \\
\hline $10 / 30 / 1999$ & 0600 & 20.50 & 85.80 & 55 & - & Tropical storm \\
\hline $10 / 30 / 1999$ & 1200 & 20.30 & 85.80 & 45 & - & Tropical storm \\
\hline 10/30/1999 & 1800 & 20.20 & 85.90 & 45 & - & Tropical storm \\
\hline 10/31/1999 & 0000 & 19.90 & 85.90 & 40 & - & Tropical storm \\
\hline 10/31/1999 & 0600 & 19.60 & 85.90 & 40 & - & Tropical storm \\
\hline 10/31/1999 & 1200 & 19.20 & 85.80 & 35 & - & Tropical storm \\
\hline 10/31/1999 & 1800 & 19.00 & 85.60 & 35 & - & Tropical storm \\
\hline 11/01/1999 & 0000 & 18.90 & 85.50 & 30 & - & Tropical depression \\
\hline 11/01/1999 & 0600 & 18.60 & 85.30 & 25 & - & Tropical depression \\
\hline 11/01/1999 & 1200 & 17.90 & 85.10 & 25 & - & Tropical depression \\
\hline 11/01/1999 & 1800 & 17.00 & 84.90 & 25 & - & Tropical depression \\
\hline
\end{tabular}

developed to infer the missing parameters, such as the wind-pressure relationship (Mishra and Gupta 1976; Atkinson and Holliday 1977; Courtney and Knaff 2009) for $V_{\max }$ and the pressure deficit and latitude relationship (MacAfee and Pearson 2006; Willoughby et al. 2006; Vickery et al. 2009; Spentza et al. 2012) for $R_{m}$ estimation. Unfortunately all these relations are based on datasets of varying quality and with a lack of suitable observational data that makes validation difficult (Knaff et al. 2010). Moreover, it may be noted that the generation of the wind fields around TC's can be accurately depicted using a wind field model, if the input parameters are accurately determined and assigned in the model. In the present study, the $R_{o}$ is approximated as the outermost closed isobar around the storm basing on the observed (Mandal et al. 2006) and modeled pressure field (Kalsi 2006) analyses. Mandal and Gupta (1993) have reported the diameter of area of $17 \mathrm{~m} / \mathrm{s}$ wind as the size indicator for the TC's originating in BoB (NIO) and indicated that size varied from 250 to $750 \mathrm{~km}$ for peak wind intensity ranging from 58 to $70 \mathrm{~m} / \mathrm{s}$. Carr and Elsberry (1997) and Knaff et al. (2010) have explained in details about the TC size estimation approaches in their studies. $R_{m}$ was estimated using the working track information's in this study Spentza et al. (2012). Spentza et al. (2012) established the relationship between the $V_{\max }$ and latitude of the storm track for the estimation of $R_{m}$ for TC's of all the major oceanic basins by utilizing the IBTrACS (Knapp et al. 2010) data. This relationship was verified against Willoughby et al.'s (2006) formula for North Atlantic basin TC's. 
The TC wind fields are generated by taking into account the cyclone parameters such as size $\left(R_{o}\right)$, distance from the center of the cyclone $(r)$, radius of maximum wind $\left(R_{\mathrm{m}}\right)$, translational velocity $\left(\mathrm{V}_{t}\right)$ and Coriolis parameter $(f)$. The model cyclone has tangential $v_{c}$ and radial $u_{c}$ wind components varying with the radial distance $(r)$ are given as follows:

$v_{c}(r)=\frac{f_{0}}{2}\left[R_{0}\left(\frac{R_{0}}{r}\right)^{X}-r\right] \frac{\alpha^{4}}{1+\alpha^{4}}$,

$u_{c}(r)=\tan (\gamma) v_{c}(t)$

where $\gamma=$ inflow angle of the wind, $a=r / R_{\mathrm{m}}$ (scaling factor), $X=$ positive constant $<1$ and taken as $X=0.4$, as proposed by Carr and Elsberry (1997). The superimposition of the synthetic wind field with real time QSCAT/ NCEP wind data is done in a line similar to Chu et al. 2000, as follows.

$\mathrm{V}=(1-\varepsilon)\left(\mathrm{V}_{c}+\mathrm{V}_{t}\right) \varepsilon \mathrm{V}_{b g}$,

where $\mathrm{V}_{b g}=$ background wind field, $\mathrm{V}_{t}=$ storm translational velocity, and ' $\varepsilon$ ' is computed by

$\varepsilon=\frac{c^{4}}{1+c^{4}} \quad c=\frac{r}{0.9 R_{0}}$.

where the other symbols have their usual meanings.

Tropical cyclone wind profile model (Carr and Elsberry 1997) is physically-meaningful storm centered model based on the angular momentum balance to compute the wind vector relative to the center of the tropical cyclone to establish a high-resolution surface wind fields for TC's. The best track storm course and speed from JTWC is used to determine the components of translational vector. This component of the model produces a distinct asymmetrical wind structure of a moving cyclone. The translational velocity of the system translating along the northwest direction causes enhanced wind flows on the right side of the moving storm and diminished wind flow on the left side in northern hemisphere (Veneziano 1998). This asymmetrical wind forcing contributes significantly in exhibiting the impact of the storm surge/SSH variations.

\section{Simple characteristics of the TCWM}

The characteristics of the TC winds and their structures changes with the varied values of input parameters: $R_{\mathrm{o}}, R_{\mathrm{m}}$, and constant $X$ etc. in TCWM. Figure 4 shows the symmetric and asymmetric TC wind profiles representative for 27 October (1200 UTC) 1999. The parameters: $R_{\mathrm{o}}=700 \mathrm{~km}, R_{\mathrm{m}}=25 \mathrm{~km}$ and varied $X$ values (i.e., $X=0.35, X=0.40$ and $X=0.45$ ) were used in generating the wind profiles. The magnitude of the modeled wind in the asymmetric profiles (right) show higher values as

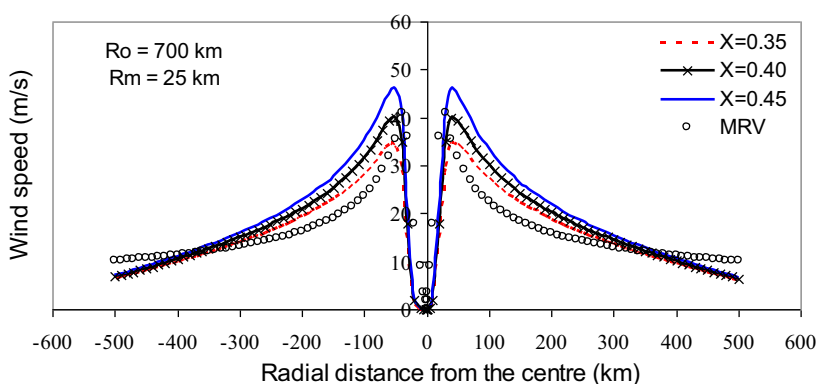

(a) Symmetric

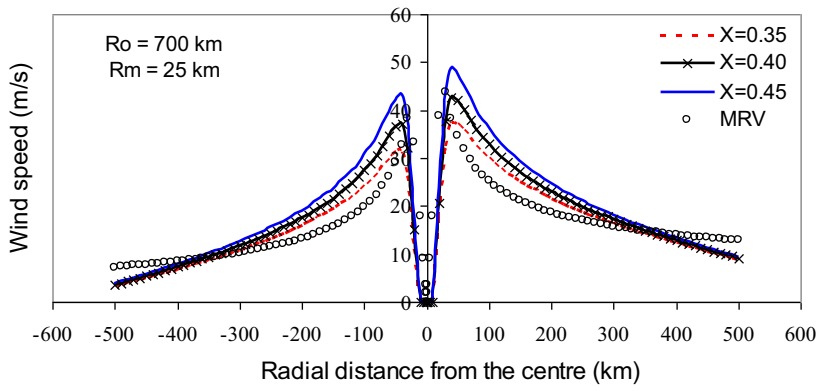

(b) Asymmetric

Fig. 4 Modeled wind profiles for varying $X$ representative for 1200 UTC of 27 October 1999. a Left (symmetric) and b Right (asymmetric)

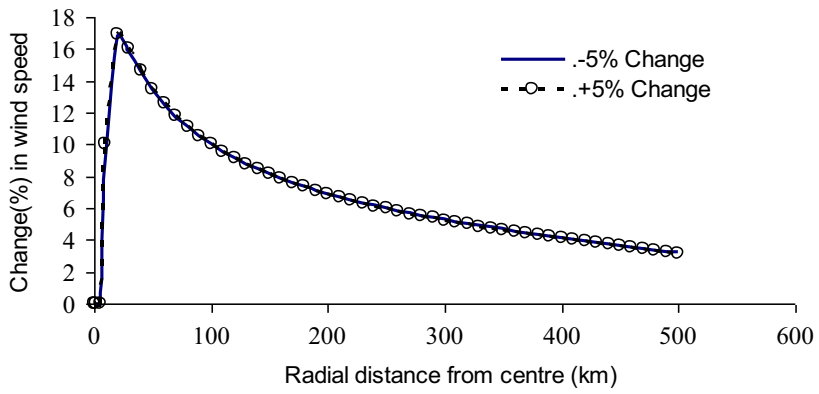

Fig. 5 Wind speed changes (\%) with changes in X

compared to the symmetric one (left). However, in both the figures modeled wind profiles vary with $X$ indicating that the profiles have different values with different $X$ 's. For example, when $X$ is changed from 0.40 to 0.35 (reduced by 0.05 ) and 0.40 to 0.45 (increased by 0.05 ), the magnitude of the wind show lower and higher values, respectively (Fig. 4), however difference in intensity is almost negligible (Fig. 5). It can be seen that the wind speed increases steeply as $r$ approaches $R_{m}$ and values are mostly lower beyond the $R_{m}$ in all the profiles. Radial profile of tangential winds based on Modified Rankine (Rankine 1982) Vortex (MRV) model (Holland 1980) was also generated by using the working storm parameters for the same period, which show a close fit at $X=0.40$ (Fig. 4). MRV is chosen because of its mathematical simplicity and viable for 
different applications. The value of $X=0.40$ is found to be sufficiently accurate as proposed by Carr and Elsberry 1997. Das et al. (2014) and Veneziano (1998) have also used $X=0.40$ in their studies. Wind model formulation based on Chan and Williams (1987) was used by Carr and Elsberry (1997) to compare with the wind profile he generated and noticed the differences in outer wind structure, though matching was good. However, it may also be noted that although, the peak wind velocity due to MRV is more or less in agreement with TCWM at $X=0.40$, the outer wind structure do not fit fairly well. Importantly, a variation of $X$ from 0.35 to 0.45 for model derived wind profiles of same extent $R_{o}$ has a relatively small effect on the strength of the winds at radii outside $350 \mathrm{~km}$ (Fig. 5). Figure 6 shows the example of the wind profile variation with radius for different values of $R_{o}$ in a storm with $R_{m}=25 \mathrm{~km}$ and $X=0.40$. From the Fig. 6 , it is clear that winds are small at large radii, and thus frictional effects are small. The wind profile is determined by conservation of earth angular momentum that the air parcel has at the radius $R_{o}$ where the relative angular momentum is equal to zero (Stenger and Elsberry 2014). The outer wind increases almost linearly with radius towards the center of the TC. In the inner core region, where frictional influences are large and angular momentum is not conserved and wind speed increases more rapidly towards the center. Though, modeled wind profiles show that the outer and inner core wind structure vary together. That is, the physical processes that increase/decrease the intensity would have a corresponding increase/decrease in the entire wind structure (Stenger and Elsberry 2014). Similarly, with increasing $R_{\mathrm{m}}$ values the peak wind speed diminishes, which show the inverse relationship (Fig. 7). Beyond approximately $70 \mathrm{~km}$ of radius, intensity appears almost same for all the considered values of $R_{\mathrm{m}}$.

Figure 8 illustrates the two-dimensional modeled wind field representing the cyclonic vortex for 27 October (1200 UTC) 1999. Parameters: $X=0.40, R_{o}=700 \mathrm{~km}$ and $R_{m}=25 \mathrm{~km}$ were used in generating both the symmetric (left) and asymmetric (right) wind fields (Fig. 8). In both the figures the shaded contours represent the magnitude of

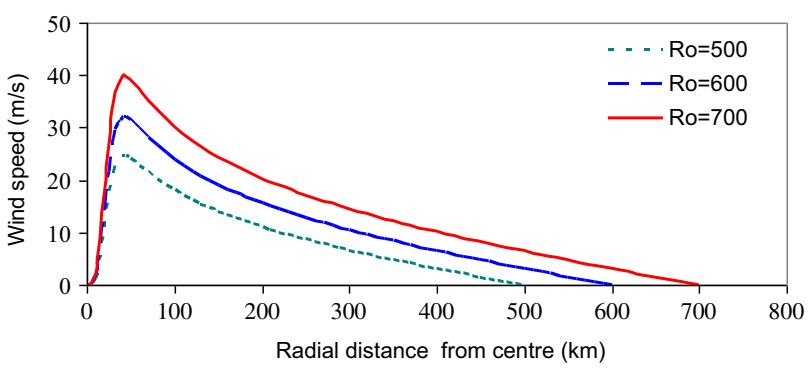

Fig. 6 Wind profiles for varying radial extents $\left(R_{o}\right)$ with $X=0.4$

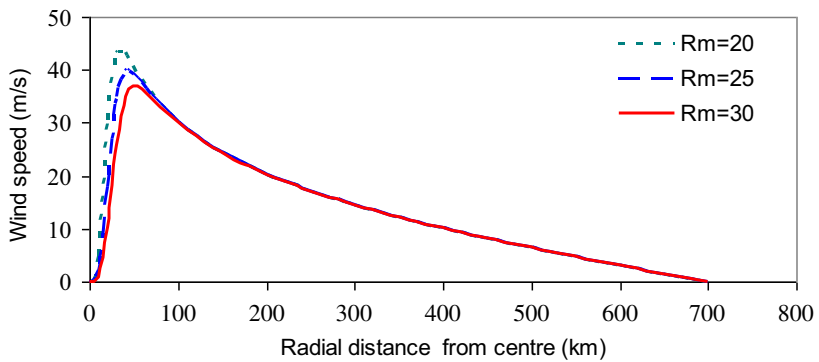

Fig. 7 Wind profiles for varying radius of maximum winds $R_{m}$ with $\mathrm{X}=0.4$

the TC winds at different radii, whereas, the arrows superimposed are the indicative of the relative magnitude plus direction of circulation which is anticlockwise. The magnitude of symmetric vortex is comparatively less than the asymmetric one, since the translational vector component is added up in the right quadrant in generating right asymmetry in later case representing the realistic structure of TC. Stronger winds appear in the northeast quadrant inside the $R_{m}$, as is often observed in surface wind data during a TC. The direction of system's movement is northwestwards. A fairly strong convergent flow exists in the vicinity of the surface as indicated by vector plots, which causes the transport of momentum in the radial direction in the TC boundary layer (Meng et al. 1995). In order to show the symmetric and asymmetric structure of model generated wind fields, i.e., the $u$ - and $v$ components are also mapped separately, as shown in the Figs. 9 and 10. It is clear from the figures that modeled winds are able to capture the main characteristics of the asymmetric structure and the intensity of the TC. Similar results were demonstrated for TC Earl (August, 2010) of North Atlantic basin (Probst and Franchello 2012).

Hence, TC model generated 6-hourly asymmetric winds from 25-29 October 1999 were superimposed with QSCAT/NCEP blended ocean surface winds for the same duration and resolution and used in driving the ocean model as realistic cyclonic winds. QSCAT/NCEP blended ocean wind data from Colorado research Associates are derived from spatial blending of high-resolution satellite data (Seawinds instruments of the QuickSCAT satelliteQSCAT) and global weather center re-analysis (NCEP). They have global coverage with high temporal and spatial resolutions (6-hourly and $\left.0.5^{\circ} \times 0.5^{\circ}\right)(\mathrm{http}: / / \mathrm{drs}$.ucar.edu/ datasets/ds744.4). Quality control of this global uniform coverage data is based on Chin et al. 1998; Milliff et al. 2004. The 6-hourly superimposed winds from 00UTC of 26 to 1800 UTC of 29 October 1999 are generated, however, representative plots at 00UTC on 26, 27, 28 and 29 October 1999 only are shown in Fig. 11 (6-hourly superimposed wind plots from 25 to 29 October are not shown for 
Fig. 8 Wind model generated wind fields for TC05B, 1999.

a Symmetric (left) and

b Asymmetric (right),

representative for the 27

October (1200 UTC), 1999. The reference vector scale is $45 \mathrm{~m} / \mathrm{s}$

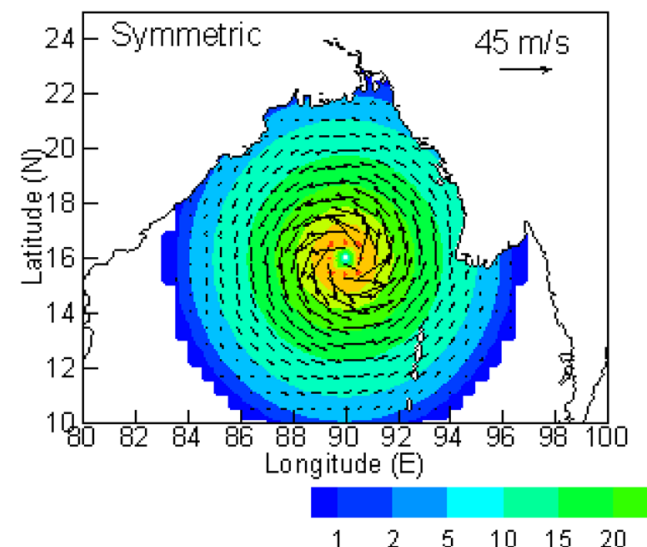

(a) Symmetric

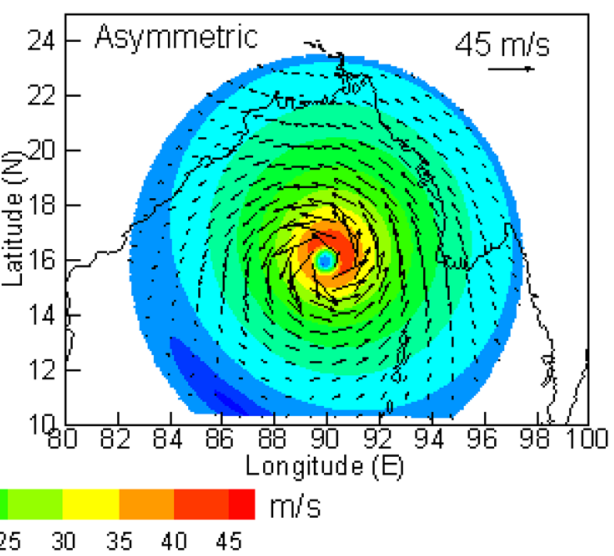

(b) Asymmetric
Fig. 9 Wind model generated symmetric wind fields for TC05B 1999. a u-component (x-direction), b v-component (y-direction) representative for the 27 October (1200 UTC), 1999
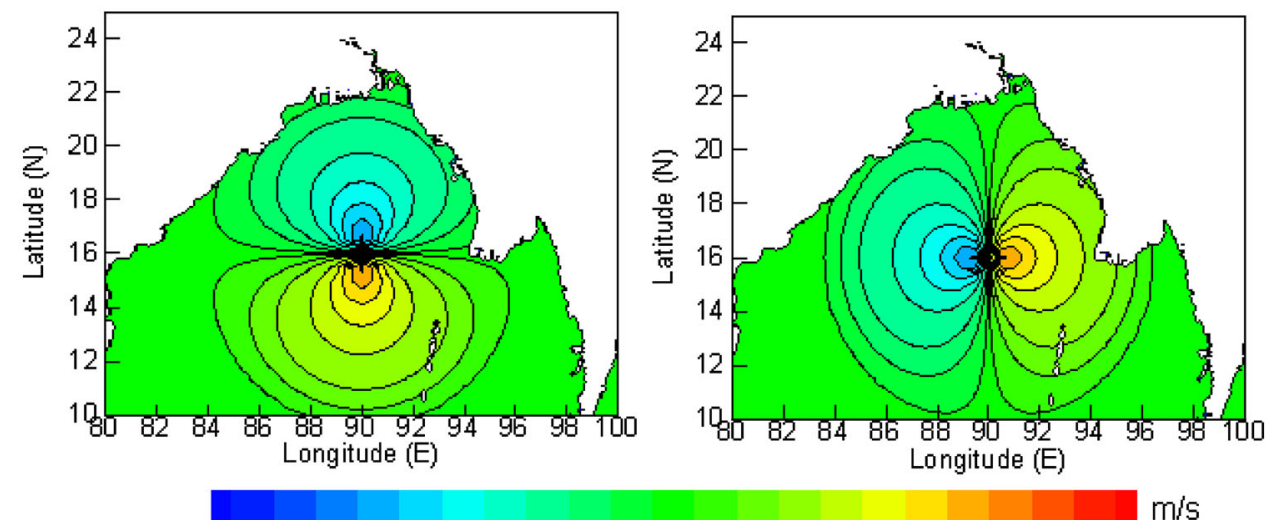

$-45-40-35-30$

(a) u-component

(b) v-component
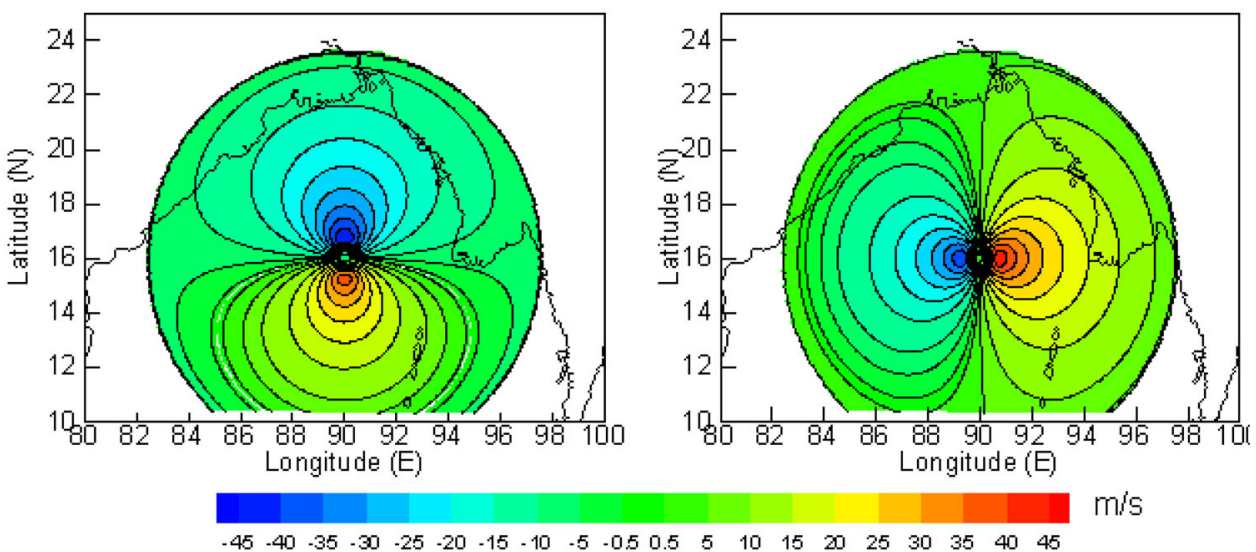

(a) $\mathrm{u}$-component
Fig. 10 Wind model generated asymmetric wind fields for TC05B 1999. a u-component (x-direction), b v-component (y-direction) representative for the 27 October (1200 UTC), 1999 simplicity and brevity of the manuscript). Reference wind vector (arrow) representing the magnitude of wind velocity is $45 \mathrm{~m} / \mathrm{s}$ for all the plots, though magnitude varies in different days of storm passage. Color shaded contours represent the magnitude of the winds. It is obvious from the figure that superimposed winds represent the realistic TC structure and magnitude. The maximum value of superimposed wind during the entire life period of the storm was $\sim 71.43 \mathrm{~m} / \mathrm{s}$ that is in close accordance with the JTWC reports of $\sim 70 \mathrm{~m} / \mathrm{s}$ with a difference of $\sim 2.12 \%$ 
Fig. 11 Superimposed wind fields (wind model generated winds with QSCAT/NCEP winds) for TC05B 1999. Representative for 00 UTC of 26, 27, 28 and 29 October, 1999
Table 2 Verification of modeled maximum wind speed with observation
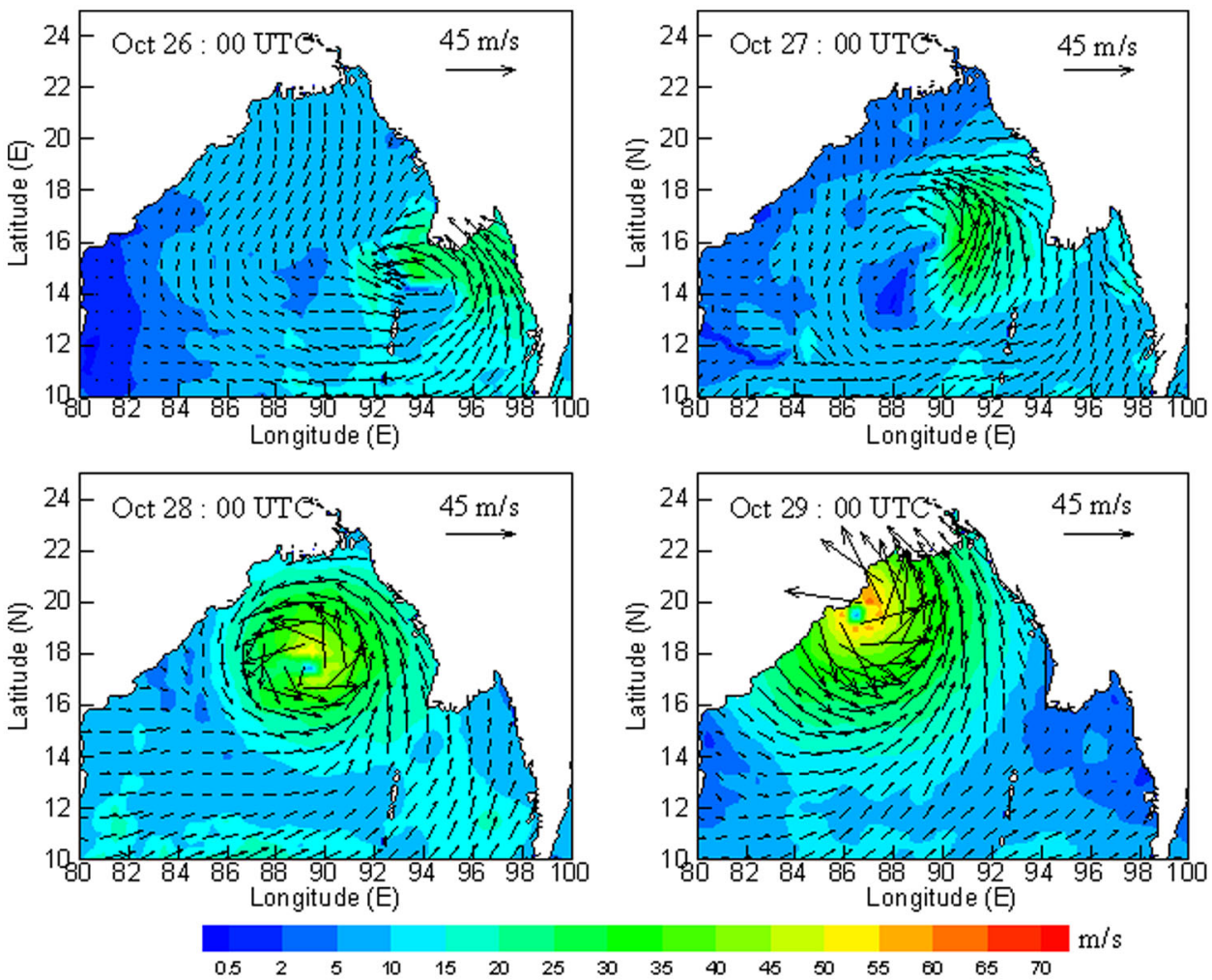

\begin{tabular}{lllll}
\hline System/status & Landfall date & \multicolumn{2}{l}{ Maximum wind speed (m/s) } & \multirow{2}{*}{ Difference (\%) } \\
\cline { 3 - 4 } & & Observed & Modeled & \\
\hline TC05B 1999/SuCS & $\begin{array}{l}\text { 10/29/1999 } \\
\text { Around noon }\end{array}$ & 70.00 & 71.49 & 2.12 \\
& Aroun & & \\
\hline
\end{tabular}

SuCS super cyclonic storm
(Table 2). Cubic spline interpolation technique is used to bring the superimposed wind fields to match the resolution of ocean model. Wang and Han (2014) superimposed the reconstructed winds with the Cross-Calibrated Multiplatform (CCMP) satellite ocean surface wind field in forcing the ocean model in their studies.

\section{The Princeton ocean model (POM)}

\section{Model description}

Ocean model (POM), developed by Blumberg and Mellor (1987) was adopted and utilized in this study. The POM is a time-dependent, primitive equation ocean model on a three-dimensional grid with complete thermohaline dynamics that includes realistic topography (terrain-following) and a free surface and the curvilinear orthogonal coordinate in the horizontal direction to fit irregular coastal boundary. Model equations are based on certain approximations and assumptions. The approximations are based on several hypotheses. Under the hydrostatic approximation, it is assumed that vertical gradient of pressure is balanced with the buoyancy force considering the horizontal dimensions are more important than vertical dimensions. By considering the ocean as shallow waters the NavierStocks equations is simplified on the vertical. Furthermore, Sea water is considered as an incompressible fluid, which is equivalent to the Boussinesq approximation that assumes density, is relatively constant in space and time except when it is multiplied by the gravity acceleration in calculation of pressure. The POM includes an embedded second order turbulence sub-model (the level 2.5 Mellor-Yamada scheme; Mellor and Yamada 1982) to provide vertical turbulent diffusion coefficient. The Smagorinski (1963) formula is used to calculate horizontal diffusion coefficient. The model uses a splitting mode time steps. The external mode of the model is depth averaged to predict free water 
Table 3 Model attributes

\begin{tabular}{ll}
\hline Model type/code & Primitive equations, free surface/stand alone \\
Vertical grid & Sigma $(\sigma),(\sigma=\mathrm{Z}-\eta / \mathrm{H}+\eta)$ \\
Horizontal grid & C-grid, curvilinear (orthogonal) \\
Vertical mixing & Mellor Yamada (2.5) \\
Horizontal mixing & Smagorinsky \\
Advection scheme & 2nd order centred \\
Time-stepping & Standard leap-frog \\
Time steps mode & $\begin{array}{l}\text { Split mode: baroclinic/internal \& barotropic/ } \\
\text { external }\end{array}$ \\
\hline
\end{tabular}

surface. The solution to the external mode is entirely explicit. The internal mode is three dimensional to compute three velocity components and water surface elevation (Mellor and Yamada 1982). Model did not include the tidal forcings and river outflow in the present application.

Model attributes are given in Table 3. Basic equations, that is, the continuity, momentum conservation and temperature and salinity equations (Blumberg and Mellor 1987; Mellor 2001) in Cartesian coordinate system in simplified form can be represented as,

Continuity equations

$\frac{\partial u}{\partial x}+\frac{\partial v}{\partial y}+\frac{\partial w}{\partial z}=0$.

$\mathrm{X}$-momentum equation

$\frac{d u}{d t}=-\frac{1}{\rho_{0}} \frac{\partial p}{\partial x}+f v+\frac{\partial}{\partial z}\left(A_{m v} \frac{\partial u}{\partial z}\right)+F_{x}$,

Y-momentum equation

$\frac{d v}{d t}=-\frac{1}{\rho_{0}} \frac{\partial p}{\partial y}+f u+\frac{\partial}{\partial z}\left(A_{m v} \frac{\partial v}{\partial z}\right)+F_{y}$,

Z-momentum or hydrostatic equation

$\frac{\partial p}{\partial z}=-\rho g$

Temperature equation

$\frac{d T}{d t}=\frac{\partial}{\partial z}\left(A_{h v} \frac{\partial T}{\partial z}\right)+F_{T}$,

Salinity equation

$\frac{d S}{d t}=\frac{\partial}{\partial z}\left(A_{h v} \frac{\partial S}{\partial z}\right)+F_{S}$,

Equation of state

$\rho=\rho(T, S, z)$,

The terms $d(\cdot) / d t, F_{x}, F_{y}, F_{T}$ and $F_{S}$ presented in the Eqs. (2), (3), (5) and (6) represent the total derivative terms, these unresolved processes and in analogy to the molecular diffusion can be described as
$F_{x}=\frac{\partial}{\partial x}\left[2 A_{m} \frac{\partial u}{\partial x}\right]+\frac{\partial}{\partial y}\left[A_{m}\left(\frac{\partial u}{\partial y}+\frac{\partial v}{\partial x}\right)\right]$,

$F_{y}=\frac{\partial}{\partial y}\left[2 A_{m} \frac{\partial v}{\partial y}\right]+\frac{\partial}{\partial x}\left[A_{m}\left(\frac{\partial u}{\partial y}+\frac{\partial v}{\partial x}\right)\right]$,

and

$F_{T, S}=\frac{\partial}{\partial x} A_{h} \frac{\partial(T, S)}{\partial x}+\frac{\partial}{\partial y} A_{h} \frac{\partial(T, S)}{\partial y}$.

where $u, v=$ the horizontal components of the velocity vector, $w=$ the vertical component of the velocity vector, $g=$ the gravitational acceleration, $p=$ the local pressure, $\rho(x, y, z, t, T, S)=$ the local density, $\rho_{o}=$ the reference water density, $A_{m}=$ the horizontal turbulent diffusion coefficient, $A_{m v}=$ the vertical turbulent diffusion coefficient, $f=2 \Omega \sin \theta$ is the Coriolis parameter $(\theta=$ latitude, $\left.\Omega=7.2921 \times 10^{-5} \mathrm{rad} \mathrm{s}^{-1}\right), T=$ the potential temperature, $S=$ the potential salinity, $A_{h}, A_{h v}=$ the horizontal and vertical thermal diffusivity coefficients, $F_{x}, F_{y}=$ the horizontal viscosity, $F_{T}, F_{S}=$ the horizontal diffusion terms of temperature and salinity.

The governing equations are then transformed from $\mathrm{z}$-coordinate $(\mathrm{x}, \mathrm{y}, \mathrm{z}, \mathrm{t})$ into the vertical sigma coordinate $\left(x^{*}, y^{*}, \sigma, t^{*}\right)$ by the relation

$x^{*}=x, y^{*}=y, \sigma=\frac{z-\eta}{H+\eta} \quad$ and $\quad t^{*}=t$,

where $H(x, y)$ is the bottom topography, $\eta$ is the sea surface elevation. The value of sigma ranges from $\sigma=0$ at $\mathrm{z}=\eta$ to $\sigma=-1$ at $\mathrm{z}=-H(x, y)$.

To examine the wind induced currents a three-dimensional model is used in majority of storm surge calculation. However, changes in sea surface elevation are expressed by vertically integrating the equations and expressing the bottom stress in terms of the depth mean currents in twodimensional form (Aschariyaphotha et al. 2013).

\section{Model configuration and boundary conditions}

The model used in this study extends from $10.0^{\circ}$ to $22.0^{\circ} \mathrm{N}$ and $80.0^{\circ}$ to $100.0^{\circ} \mathrm{E}$ (Fig. 1) that uses orthogonal curvilinear grid with Arakawa C-grid staggering, with a variable horizontal grid resolution of $4-12 \mathrm{~km}$. The model has $250 \times 250$ horizontal grid points and 26 sigma layers in the vertical. The model uses the bottom topography derived from the Earth Topography and Ocean Bathymetry Database (ETOPO5) at 5-min resolution from NOAA/NGDC (http://www.ngdc.noaa.gov/mgg/global/soltop.html) database as shown in the Fig. 1. The ETOPO5 data are smoothed and interpolated onto the user's specified domain and grid sizes. The two-dimensional external mode uses a short time-step of $12 \mathrm{~s}$. based on the external wave speed, while a three-dimensional internal mode uses a long time- 
step of $540 \mathrm{~s}$. based on the internal wave speed. CourantFredrick-Levy (CFL) condition is followed for computational stability.

\section{Atmospheric forcing}

The atmospheric forcing includes wind and heat flux forcing for the BOB application of POM. The wind forcing applied is determined by

$\rho_{0} K_{M}\left(\frac{\partial u}{\partial z}, \frac{\partial v}{\partial z}\right)_{z=0}=\left(T_{0 x}, T_{0 y}\right)$

where $K_{M}$ is the vertical mixing coefficient for momentum, and $(u, v)$ and $\left(\tau_{O} x, \tau_{o} y\right)$ are the two components of the water velocity and wind stress vectors, respectively. To calculate wind stresses, a bulk formula (Large and Pond 1981 ) is used for low-to-moderate winds and Powell et al. (2003) for high wind speeds. According to this formula, drag coefficient is constant at low winds, linearly increases for moderate winds, reaches a broad maximum for hurricane-force winds and decreases slightly for extreme winds. Drag coefficient formula that accounts for high winds in order to simulate the ocean response due to TC are used (Oey et al. 2007). Surface thermal forcing used in this study is restoring type heat plus salinity flux forcing, following in a line similar to Chu et al. (2000) and are given in detail in Das et al. (2014). On the bottom of the BoB the normal gradients of the temperature and salinity were zero, so that there were no advective diffusive heat and salt fluxes across the boundary. The bottom stress is assumed to follow a quadratic low (Blumberg and Mellor 1987). Details on surface and bottom boundary conditions are given in Mellor (2004).

\section{Lateral boundary forcing}

The modeled ocean bordered by land (i.e. closed lateral boundaries), were defined using a no slip condition for velocity and a zero gradient condition for temperature and salinity. No advective or diffusive heat, salt or velocity fluxes occur through these boundaries. At open boundaries, when the water flows into the model domain, temperature and salinity at the open boundary are likewise prescribed from the mean monthly climatology data (Levitus and Boyer 1994). Radiative boundary conditions are prescribed for momentum and thermal variables at the lateral open boundaries when water flows out of the domain (Mellor 2001; Chu et al. 2000), the radiation condition was applied,

$\frac{\partial}{\partial t}(T, S)+U_{n} \frac{\partial}{\partial n}(T, S)=0$

where the subscript $\mathrm{n}$ is the direction normal to the boundary.

\section{Experimental setup}

The model was initialized with zero initial velocity with 3-dimensional gridded temperature and salinity monthly climatology and realistic bathymetry. The temperature and salinity data with $0.5^{\circ} \times 0.5^{\circ}$ resolution provided by Levitus94 (Levitus and Boyer 1994; Levitus et al. 1994) were used. Model was forced with QSCAT/NCEP monthly wind stress with spatial resolutions of $0.5^{\circ} \times 0.5^{\circ}$ (Chin et al. 1998; Milliff et al. 2004). In the present application, the TC spin up period was adequate for the model to reach equilibrium and to provide the results. During the simulation stage it was forced with real time 6-hourly QSCAT/ NCEP blended wind field embedded with TCWM generated vortices (Carr and Elsberry 1997) which provides the realistic cyclonic winds to BoB. Heat fluxes used were taken from COADS climatology (da Silva et al. 1994). Model integration was performed starting from 00UTC, 25 October to 18UTC, 29 October. 1999. The storm surge, SSH and surface currents were output by the model. 6-hourly snapshots were stored for analysis. Results are shown from 00 UTC of 26 October to 18 UTC of 29 October for 6-hourly outputs and from 27 to 29 October for the 1-day composites.

\section{Results and discussion}

Results yielded from the model simulation on the storm surge, SSH and surface currents during TC05B, 1999 are discussed here.

Figure 12 illustrates the modeled peak surge height at 006 UTC on 29 October 1999 due to TC05B. At this time, the centre of the storm was located near Paradip (Orissa) on the east coast of India. The track of the TC as depicted by solid black line is superimposed with the storm surge plot. The open circles on the track denote the latitude/longitude positions in different days of the storm with corresponding date/time. It can be seen that as the storm approached the coast, while moving in the northwest direction, water level in the northern-rim of BoB increased. The surface water piles up due to the mass transport from offshore to onshore in generating the storm surge (Mori et al. 2014) as the storm associated strong wind stress exert parallel to the sea surface (Sinha et al. 2008). The shallower bathymetry in the continental shelf region, the coastal orientation and the basin geometry of the BoB enhanced the surface water level in northern rim. However, the maximum surge height was noticed to the right side at some distance at Orissa coast away from the track of the storm movement direction due to asymmetric onshore TC winds. The occurrence of modeled maximum surge height at some distance away from the track to the right side may be attributed to the 


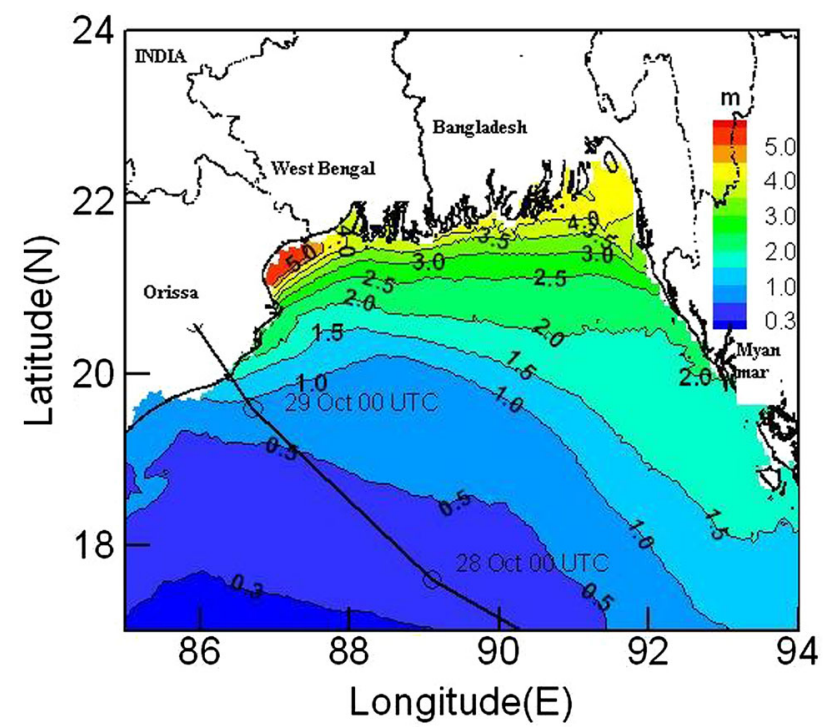

Fig. 12 Modeled peak surge height (meters). Path of TC05B 1999 is superimposed over the plotted map and black circles represents the 6-hourly positions of the cyclone in different days of its passage

coarse resolution bathymetry data. Similar results were obtained by Dube et al. $(2009,2010)$ for TC's originated in $\mathrm{BoB}$ (NIO). However, beneath the storm centre before the landfall the lower SSH values could also be seen, this may be due to strong divergence flow/upwelling. The modeled maximum surge height was $\sim 5.348 \mathrm{~m}$ as against the observed total water level of $\sim 6 \mathrm{~m}$ as provided by Paradip Port Trust (PPT) of India, 1999. Unisys Weather Information Services provides the surge height $>5.5 \mathrm{~m}$, based on the analyses of satellite/radar images and surface/upper air data. Similarly, vulnerability Atlas (BMTPC 2006) provides the probable maximum surge height in the order of $\sim 5.4 \mathrm{~m}$ along this coastline. The simulated result is comparable with the other available modeled/observed values provided by several research and Government agencies, though some agencies report the higher surge values than the present study (Table 4).

The spatial plots of 6-hourly model output on SSH superimposed with surface currents at 00UTC, 06UTC, 12UTC and 18UTC for 26, 27, 28 and 29 October, respectively, are shown in the figure (Fig. 13). In the figure, the left panels show for 00UTC and 12UTC whereas; right panels represent the 06UTC and 18UTC simulations. The shaded colour contours depict the SSH and the vector arrows represent the relative magnitudes and direction of the surface currents with reference vectors of $250 \mathrm{~cm} / \mathrm{s}$ for all the 6 -hourly plots. From the figure, it is evident that SSH is greatly modulated by strong cyclonic winds. Consequently, the strong surface currents were generated by the strong surface winds (wind stress) of the storm.

On 26 October when the system was relatively lower intense and nearer to the southern Myanmar coast
( $210 \mathrm{~km}$ southwest of Yangon, Myanmar) and northeast of Andaman Island then the eastern, northeastern and northern BoB bordering the coastline of Myanmar, Bangladesh and India (West Bengal and part of Orissa), respectively indicated the higher $\mathrm{SSH}$ values to the right of the cyclone position. This could be attributed to coastal convergence and Ekman transport through the TC induced wind stress. Surface current has followed the circulation pattern of TC wind. Moreover, the southwesterly winds play a dominant role in this case in giving rise to relatively higher values of SSH along the Myanmar and Bangladesh coast. Whereas, the western and south- west central BoB show comparatively lower values of SSH. On analyzing the SSH plots from 00UTC to 18UTC of 26 October, it is noticed that when the anticlockwise flow of the storm was closer to southern Myanmar coast the piling up of waters appears more towards the coast in giving rise to the higher values of SSH. Subsequently, as the system travels northwestwards, i.e., towards Indian coastline the higher SSH values shifts towards the northeastern, northern and northwestern part of BoB. Modeled SSH and current on 27 October from 00UTC to 18UTC show distinct sea surface modulation by the TC winds. The system gained strength on 27 October, while traversing northwestwards at the speed of $\sim 4.5 \mathrm{~m} / \mathrm{s}$. The distinct feature of the TC induced negative SSH center was exhibited by the model. Similarly, it can be seen that the anticlockwise circulation and piling up of the sea waters is more pronounced and higher (i.e. positive) SSH appeared along the northern and northeastern boarder of BoB. Along the eastern (Orissa, Andhra Pradesh and Tamilnadu) coast of India, i.e. the western parts of $\mathrm{BoB}$, the positive SSH at 00UTC, 06UTC and 12UTC is observed, in spite being in the left side of storm track. This could be attributed to the current driven coastal convergence of water masses and the counter-clockwise propagating sea-level signal around the perimeter of the $\mathrm{BoB}$ that increased the SSH along the western BoB boundary (Wang et al. 2012; Wang and Han 2014). At 18UTC the higher SSH band is not extended to southernmost part of the coast, whereas, at 12UTC the higher SSH band along the western coastal waters is more pronounced and extended to further southern parts of coastal region. However, a marked negative SSH values were also noticed along the TC centre due to surface divergence/cooling and lowering of the sea surface. On 28 October at 00UTC, when the storm gained more strength and continued to move towards the northwest direction, the higher values of SSH appeared more pronounced in the northern and northwestern part of $\mathrm{BoB}$, while retaining the higher values along the eastern parts also. At 06UTC, the nature of SSH distribution was very similar to that at 00UTC. However, the western part of BoB which showed higher SSH on 27 October is not appeared at 06UTC, 12UTC and 18UTC simulations on 28 
Table 4 Verification of modeled peak surge with estimated/observed and reported values

\begin{tabular}{llllll}
\hline Sr. No. & Organisations & Methodology & $\begin{array}{l}R_{\max } \\
(\mathrm{km})\end{array}$ & Surge height $(\mathrm{m})$ & References \\
\hline 1 & Present study & Dynamical model & 25 & 5.348 & Present study \\
2 & IITD & Dynamical model & 40 & 7.294 & Dube et al. (2009) \\
3 & NIOT/INCOIS & Dynamical model & 50 & $5-6$ & Latha and Rama Rao (2007) \\
4 & IMD & Dynamical model & 15 & 5.9 & Kalsi (2006) \\
5 & BMTPC & Vulnerability atlas & - & 5.5 & BMTPC (2006) \\
6 & MoRD & Damage survey & - & 7.5 & $*$ \\
7 & IOC-UNESCO & Report & - & $7-8$ & $* *$ \\
8 & UNISYS & Data analysis & - & $>5.5$ & Paradip Port Trust, Orissa, India \\
9 & Paradip Port Trust & Observations & - & 6.0 & MoRD
\end{tabular}

IITD Indian Institute of Technology, Delhi, India

NIOT National Institute of Ocean Technology, Chennai, India

INCOIS Indian National Centre for Ocean Information System, Hyderabad, India

$I M D$ India Meteorological Department, New Delhi, India

BMTPC: Building Material and Technology Promotion Council, New Delhi, India

MoRD: Ministry of Rural Development, New Delhi, India

IOC- UNESCO: Intergovernmental Oceanographic Commission of United Nations Educational, Scientific and Cultural Organization, Paris

UNISYS: Unisys Weather Information System, UK

* Website: http://unesdoc.unesco.org/images/0012/001204/120491E.pdf

** Website: http://weather.unisys.com

October. The more pronounced negative SSH values (comparatively more sea surface depression) were seen along the TC centers on 28 October as compared to the 27 October. At 12UTC and 18UTC, the western parts of BoB showed negative $\mathrm{SSH}$ as the cooling TC centre approaches the coast. On 29 October also similar SSH distribution pattern was indicated by the model simulation. The entire eastern and northeastern parts of BoB showed higher SSH values but the amplitude appeared comparatively lower after the landfall of the storm at 12UTC and 18UTC simulations. The lower SSH values were seen on the westcentral BoB. Left to the storms' landfall location also lower values of SSH was seen. The effect of coastal current left to the track and Ekman's effect could not be seen in giving rise the higher values of SSH on 29 October as it was the case on 27 (00UTC to 18UTC) and 28 (00UTC to 06UTC) October 1999.

Figure 14 illustrates the modeled SSH (1-Day composite) from 27 to 29 October, 1999. In the figure, the upper row (left and right panels) are model output for 27 and 28 October and lower row shows for 29 October (left panel); whereas, right panel (lower row) is the delayed mode, global, science quality AVISO (Archiving, Validation and Interpretation of Satellite Oceanographic Data) (1-Day composite) SSH for 27 October. AVISO multisatellite observed SSH is used for comparison purposes with model outputs. The AVISO provide long-term, continuous altimetry datasets by merging past and present satellites, including Jason-1, TOPEX/Poseidon, The European Remote Sensing (ERS) Satellite 1 and 2 and their successor, the Environmental Satellite (ENVISAT), and the Geodetic Satellite (GEOSAT) and its successor, the GEOSAT Follow-On (GFO). These data are available from October 1992 through present in $0.25^{\circ} \times 0.25^{\circ}$ spatial resolutions on global grids and are provided once every 7 days, although measurements may be taken up to 3 days before or after the single date displayed on the data. Details of the processing and merging of the multiple satellite data are described in Ducet et al. (2000). Calibration and validation statistics is available on the AVISO website (http://ww.aviso.oceanobs.com/duacs/ and http://coastwatc.pfeg.noaa.gov/infog/TA_sshl_las.html). Figure 14 indicate that TC-associated surface wind stress is one of the major causes for the SSH variation and redistribution of masses on different days of storm passage. It is obvious from (Fig. 14) that SSH is generally higher in the eastern to northern $\mathrm{BoB}$ and lower in the southern and western $\mathrm{BoB}$, with the lowest SSH occurring in the southwestern BoB. On 27 October, the negative SSH near the TC center during that period are large on the following day because of the slow translation speed. On 28 October, the oval-shaped negative SSH area is elongated when TC05B travels further northwestward and moves slowly along the track. The southwesterly winds during storm induce stronger Ekman transport and convergence to the coasts and thus increase onshore SSH in 
Fig. 13 Modeled 6-hourly (00, $06,12 \& 18$ UTC) SSH for 27, 28 and 29 October, 1999 superimposed with surface currents $(\mathrm{cm} / \mathrm{s})$
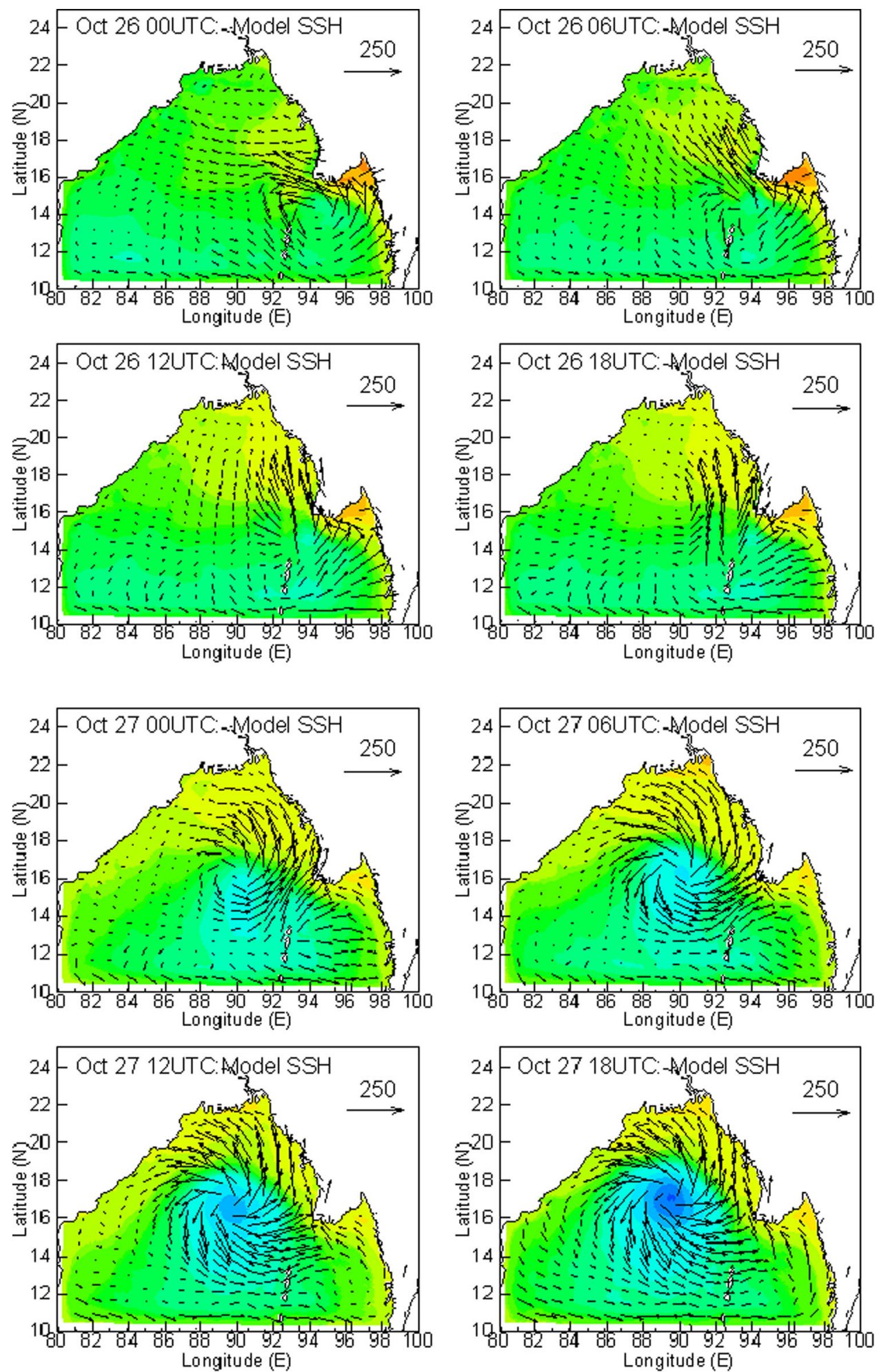

the northeastern BoB. Meanwhile, the southerly wind in the Andaman Sea piles up water to the coasts of southern Myanmar. Both processes act to increase SSH. Strong SSH gradient along the northern BoB coastline on 29 October by TC-associated wind stress causes counter clockwise surface currents along the coastline. The TC caused sea level fall along their track, similar to the effects of TC's that occur in other oceans (Prasad and Hogan 2007). The sea level rise along the rim of the BoB is slightly larger on 28 October compared to 29 October. 
Fig. 13 continued
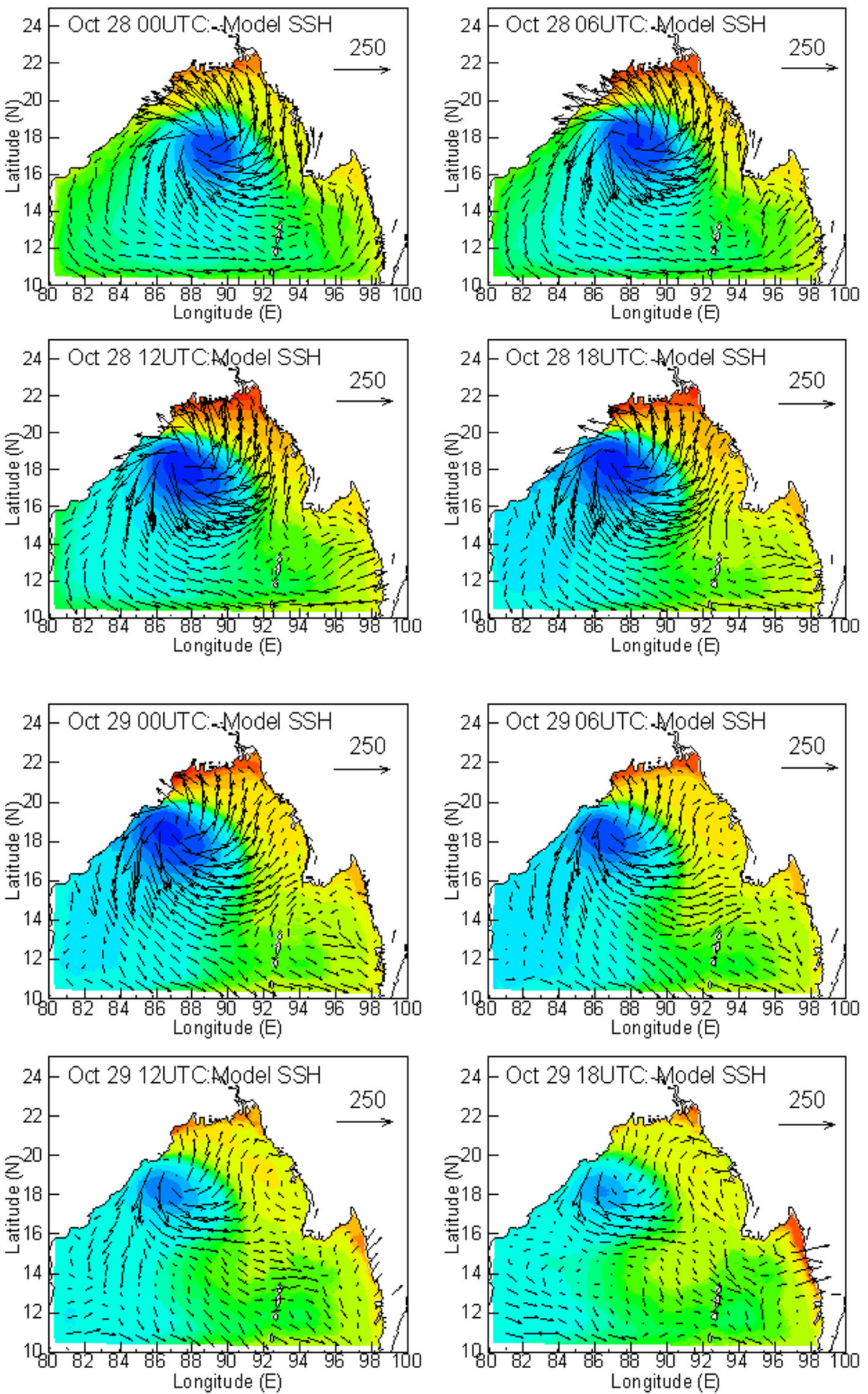

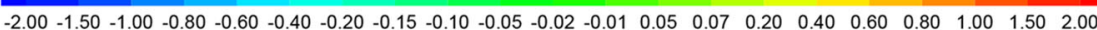

Model simulated 1-Day composite SSH are qualitatively compared with 1-Day composite AVISO multi-satellite observed SSH (of 27 October, 1999). The model outputs of 27,28 and 29 October show less coherence (not well-

(m)

resolved by the model) with AVISO SSH of 27 October (Fig. 14). No AVISO SSH observations are available on 28 and 29 October 1999. According to Wunsch and Stammer (1998) this discrepancy can be deemed as either 
Fig. 14 Comparison of modeled 1-Day composite (27, 28 and 29 October, 1999) SSH with AVISO SSH (27 October, 1999)

Fig. 15 Comparison of modeled SSH deviation with AVISO SSH deviation (27 October, 1999)
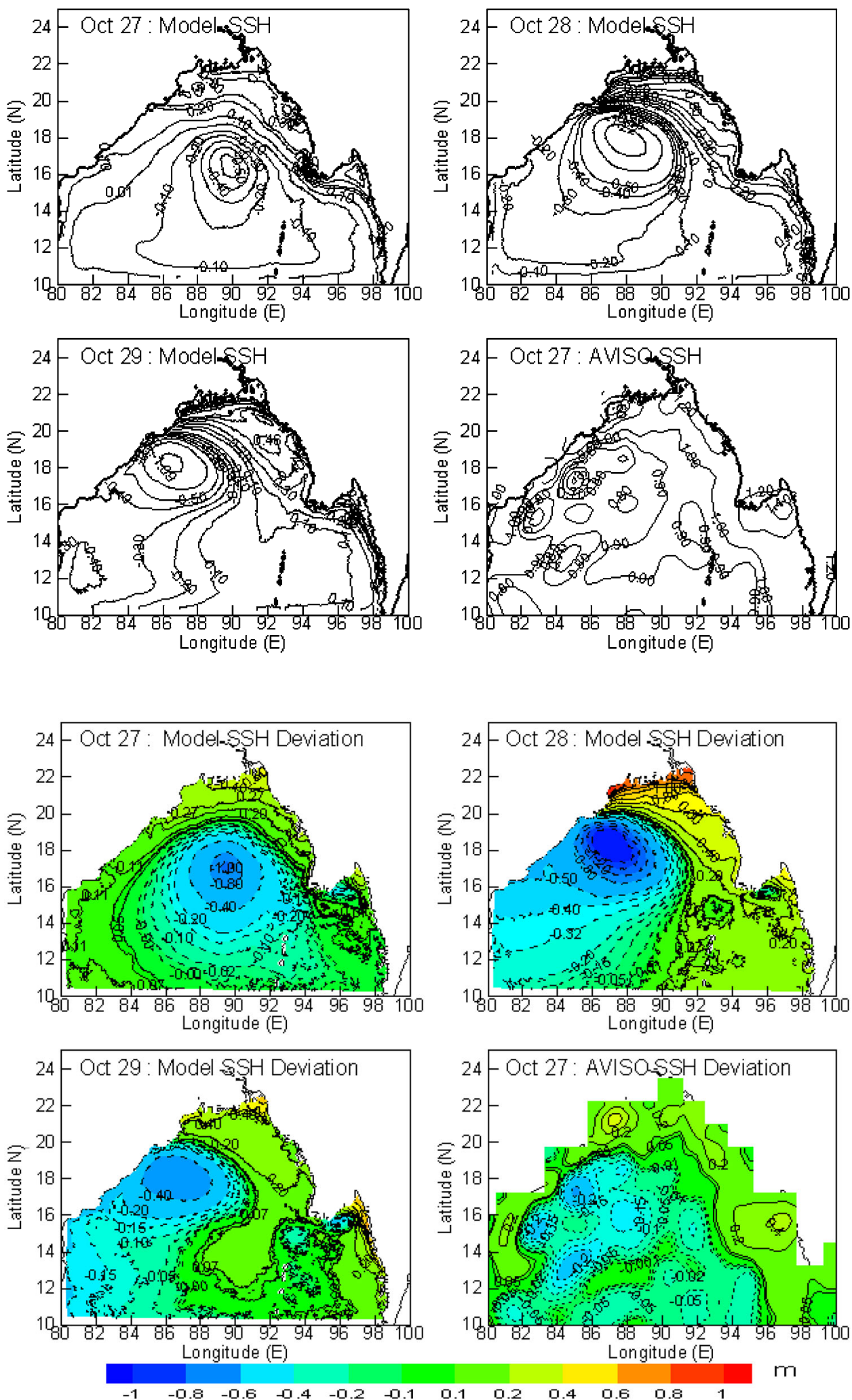

a data noise or a model deficiency. However, it may be noted that comparison with no simultaneously observed data can give an idea about the relative accuracy of the model output.
The difference between the modeled daily (1-Day) composite SSH of 25 October and 29 October is approximated as modeled SSHD (left) is compared with observed (AVISO) SSHD (right) of 27 October, 1999 (Fig. 15). 
From the modeled SSHD it is evident that the northwestern and eastern part of BoB shows the positive SSHD. However, the circular shaped higher values of SSHD appeared almost in the central part $\left(15^{\circ} \mathrm{N}, 91^{\circ} \mathrm{E}\right)$ of $\mathrm{BoB}$ and elongated to the northwestern part as a tail, whereas, the negative SSHD is noticed in the western part extending to southwest. In the AVISO data also the eastern and northeastern to upper northwestern part of $\mathrm{BoB}$ showed the higher values and westcentral part of BoB the lower values with multiple patches of negative SSHD. The circular shaped positive SSHD in AVISO data is seen very close to Myanmar coast $\left(15^{\circ} \mathrm{N}, 97^{\circ} \mathrm{E}\right)$ in the eastern $\mathrm{BoB}$ but in the modeled result, it seems shifted towards western parts and positioning almost in the central parts of BoB. AVISO data showed higher values in the southwestern part of BoB, which is not well-resolved by the model. This discrepancy could be due to the approximated SSHD by assuming model output difference between 25 and 29 October and limitations in model (non inclusions of river discharge and tidal constituents) in the present study. Yang et al. (2002) investigated the seasonal variations of $\mathrm{SSH}$ and $\mathrm{SSH}$ anomaly in SCS using POM model and obvious discrepancy was reported between the observed and modeled SSH anomaly.

\section{Conclusions}

This study addresses the simulation of storm surge, SSH and surface current over BoB during super cyclone TC05B, 1999 using POM. TC05B was one of the most significant and devastating cyclones with Category 5 status that moved in the northwest direction starting from Andaman seas and crossed the eastern coastal state Orissa of India. TC wind field was developed based on the formulation of conservation of angular momentum balance using the input parameters from the best track information's of JTWC. Model generated cyclonic winds are then embedded with the QSCAT/NCEP blended ocean surface winds to provide the realistic cyclonic wind to POM as surface forcing. Modeled peak storm surge show the higher values to the right of the storm track due to the strong asymmetric wind stress forcing. The 6-hourly and 1-Day composite model SSH indicated the higher values of SSH along the eastern, northeastern and northern coastal boundaries of BoB due to the southwesterly and southeasterly winds which help in piling-up the water masses along the coast. The anticlockwise cyclonic winds give rises the onshore Ekman transport and thus mass convergence which also enhances the SSH. The counter-clockwise propagating sea-level signal around the perimeter of the $\mathrm{BoB}$ increase the $\mathrm{SSH}$ along the western BoB boundary. However, as the storm accelerated northwestwards, part of south-west central BoB showed the lower values of SSH due to surface divergence/upwelling and cooling by strong TC winds. Similarly, along the TC centers lower values of SSH is noticed. Modeled maximum surge height is in good agreement with the limited available observed/estimated values. Modeled SSH/SSHD show less coherence (not well-resolved by the model) with the AVISO multi-satellite observed SSH/SSHD. However, variations in SSH and SSHD during TC were well represented by the model with some discrepancy with observations.

The impacts of tide and river outlet have not been considered in this study to avoid the complexity. Comprehensive studies on storm surges and SSH may be examined by considering more TC cases using coupled model with high resolution data. Sensitivity studies with modeled wind fields and QSCAT/NCEP winds as separate experiment may be examined. However, studies on storm surges are important for the coastal hazard monitoring and assessment and SSH height variations are of great significance in delineating the TC genesis and intensification processes.

Acknowledgments Ministry of Science and Technology (Science and Engineering Research Council), Government of India is sincerely acknowledged for partial research Grant (No. SR/FTP/ES-019/2003) under the way of SERC_FTYS program and CAS, IIT Delhi for availing the research facilities. Thanks are gratefully acknowledged to Atmospheric and Oceanic Sciences Program of Princeton University, the Geophysical Fluid Dynamics Laboratory of NOAA and Dynalysis of Princeton for POM. Thanks are also gratefully acknowledged to NGDC for bathymetry and other data, UCAR for QSCAT/NCEP (NASA Quikscatterometer team) data, AVISO for SSH data and IMD and JTWC for cyclone track data.

\section{References}

Ali A (1979) Storm surges in the Bay of Bengal and some related problems. PhD Thesis, University of Reading England, p 227

Ali MM, Jagadeesh PSV, Jain S (2007) Effects of eddies on Bay of Bengal cyclone intensity. Eos Trans 88(8):93-95

Anthes RA (1982) Tropical cyclones their evolution structure and effects. Meteor Monogr, No 41, Amer Meteor Soc, Boston, p 208

Aschariyaphotha NS, Klanklaew B, Wichianchai Wanchaijiraboon S (2013) Statistical analysis of sea surface elevation in numerical ocean model for the gulf of Thailand during Typhoon Muifa. Appl Math Sci 7(16):751-764

Atkinson GD, Holliday CR (1977) Tropical cyclone minimum sea level pressure/maximum sustained relationship for the Western North Pacific. Mon Wea Rev 105:421-427

Balaguru K, Chang P, Saravanan R, Leung LR, Xu Z, Li M, Hsieh J-S (2012) Ocean barrier layers effect on tropical cyclone intensification. Proc Natl Acad Sci 109(36):14343-14347

Balaguru K, Taraphdar S, Leung LR, Foltz GR (2014) Increase in the intensity of Postmonsoon Bay of Bengal tropical cyclones. Geophys Res Lett 41:3594-3601. doi:10.1002/2014GL060197

Bessafi M, Wheeler MC (2006) Modulation of south Indian Ocean tropical cyclones by the Madden-Julian Oscillation and convectively coupled equatorial waves. Mon Wea Rev 134:638-656

Blain C, Westerink JJ, Luettich RA, Scheffner NW (1994) ADCIRC: an advanced three-dimensional circulation model for shelves, 
coasts, and estuaries. Report 4. Hurricane storm surge modeling using large domains. Washington DC, 20314-1000, US Army Corps of Engineers

Blumberg AF, Mellor GL (1987) A description of a three-dimensional coastal ocean circulation model. In: Heaps NS (ed) Threedimensional coastal ocean models. American Geophysical Union, vol 4, Washington DC, pp 1-16

BMTPC (2006) Vulnerability atlas of India. Ministry of housing and urban poverty alleviation. Government of India, New Delhi, pp $1-712$

Bunya S, Dietrich JC, Westerink JJ et al (2010) A high-resolution coupled riverine flow, tide, wind, wind wave and storm surge model for southern Louisiana and Mississippi, part I: model development and validation. Mon Wea Rev 138:345-377

Cardone VJ, Cox AT (2009) Tropical cyclone wind field forcing for surge models critical issues and sensitivities. Nat Hazards 51:29-47

Carr LE III, Elsberry RL (1997) Models of tropical cyclone wind distribution and beta-effect propagation for application to tropical cyclone track forecasting. Mon Wea Rev 125:3190-3209

Chan JC-L, Gray WM (1982) Tropical cyclone movement and surrounding flow relationships. Mon Wea Rev 110:1354-1374

Chan JC-L, Williams RT (1987) Analytical and numerical studies of the beta-effect in tropical cyclone motion, part I: zero mean flow. J Atmos Sci 44:1257-1265

Chelton DB, Schlax MG (1996) Global observations of oceanic Rossby waves. Science 272:234-238

Chin TM, Milliff RF, Large WG (1998) Basin-scale high-wave number sea surface wind fields from a multiresolution analysis of Scatterometer data. J Atmos Ocean Technol 15:741-763

Chu PC, Veneziano JM, Fan C (2000) Response of the south China sea to tropical cyclone Ernie 1996. J Geophys Res 105(C6): 13991-14009

Courtney J, Knaff JA (2009) Adapting the Knaff and Zehr windpressure relationship for operational use in tropical cyclone warning centres. Aust Meteorol Oceanogr J 58:167-179

CRRI (2013) Central Road Research Institute Report: Guideline for planning and construction of roads in cyclone prone areas, pp 1-62

Crutcher HL, Quayle RG (1974) Mariners worldwide guide to tropical storms at sea. US Govt Printing Office, Washington DC, 311 Charts, pp 1-114

da Silva AM, Young CC, Levitus S (1994) Atlas of surface marine data 1994, volume 3: anomalies of heat and momentum fluxes. NOAA Atlas NESDIS 8. US Department of Commerce, NOAA NESDIS, Washington DC

Das PK, Dube SK, Mohanty UC, Rao AD (1983) Numerical simulation of the surge generated by the June 1982 Orissa cyclone. Mausam 34:359-366

Das Y, Mohanty UC, Jain I, Rao MS, Murty ASN (2014) Modeling on the aspects of thermal response of Bay of Bengal to tropical cyclone TC05B 1999 using Princeton Ocean Model (POM): preliminary results. Am J Model Opt 2(2):47-59. doi:10.12691/ ajmo-2-2-2

DeMaria M, Aberson SD, Ooyama KV, Lord SJ (1992) A nested spectral model for hurricane track forecasting. Mon Wea Rev 120:1628-1643

DeMaria M, Baik J-J, Kaplan J (1993) Upper-level angular momentum fluxes and tropical cyclone intensity change. $\mathrm{J}$ Atmos Sci 50:1133-1147. doi:10.1175/1520-0469(1993)050<1133: ULEAMF $>2.0 . \mathrm{CO} ; 2$

Dietrich JC, Bunya S, Westerink JJ et al (2010) A high resolution coupled riverine flow, tide, wind, wind wave and storm surge model for southern Louisiana and Mississippi. Part II-synoptic description and analyses of Hurricanes Katrina and Rita. Mon Wea Rev 138:378-404
Dietsche D, Hagen SC, Bacopoulos P (2007) Storm surge simulation for hurricane Hugo (1989) on the significance of inundation areas. J Waterw Port Coast Ocean Eng 133(3):183-191

Dube SK, Chittibabu P, Sinha PC, Rao AD, Sinha PC, Murty TS (2000) Extreme sea levels associated with severe tropical cyclones hitting Orissa coast of India. Mar Geodesy 23:75-90

Dube SK, Chittibabu P, Sinha PC, Rao AD, Murty TS (2004) Numerical modelling of storm surge in the head Bay of Bengal using location specific model. Nat Hazards 31(2):437-453

Dube SK, Jain I, Rao AD, Murty TS (2009) Storm surge modelling for the Bay of Bengal and Arabian Sea. Nat Hazards 51(1):3-27

Dube SK, Murty TS, Feyen J, Harper B, Bales J, Amer S (2010) Storm surge modeling and applications in coastal areas. In: Chan J, Kepert J (eds) Global perspectives on tropical cyclones from science to mitigation. World Scientific Publishing Company, Singapore, pp 363-406

Ducet N, Le Traon PY, Reverdin G (2000) Global high resolution mapping of ocean circulation from the combination of T/P and ERS-1/2. J Geophys Res 105:19477-19498

Elsberry RL, Frank WM, Holland GJ, Jarrell JD, Southern RL (1987) A global view of tropical cyclones. University of Chicago Press, Chicago, pp 1-185

Emanuel K (2003) Tropical cyclones. Annu Rev Earth Planet Sci 31:75-104. doi:10.1146/annurev.earth.31.100901.141259

Flather RA (1994) A Storm surge prediction model for the northern Bay of Bengal with application to the cyclone disaster in April 1991. J Phys Ocean 24:172-190

Frank WM (1977) The structure and energetics of the tropical cyclone II. Dynamics and energetics. Mon Wea Rev 105:136-150

Frank WM, Roundy PE (2006) The role of tropical waves in tropical cyclogenesis. Mon Wea Rev 134:2397-2417. doi:10.1175/ MWR3204.1

Fujita T (1952) Pressure distribution within typhoon. Geophys Mag 23:437-451

Gera A, Mitra AK, Mahapatra DK, Ali I, Rajagopal EN, Basu S (2013) Sea surface height and upper ocean heat content variability in Bay of Bengal during contrasting monsoons 2009 and 2010. NMRF/ RR/OCN-1/2013 NCMWRF, MoES, India, pp 1-27

Ghosh SK (1985) Probable maximum surges on the coasts of India and Bangladesh. In: Sinha DK (ed) Aspects of mechanics. South Asian Publisher, pp 73-92

Girishkumar MS, Ravichandran M (2012) The influence of ENSO on tropical cyclone activity in the Bay of Bengal during OctoberDecember. J Geophys Res 117:C02033. doi:10.1029/2011JC007417

Glahn B, Taylor A, Kurkowski N, Shaffer WA (2009) The role of the SLOSH model in National Weather Service storm surge forecasting. Natl Weather Dig 33(1):1-14

Gray WM (1975) Tropical cyclone genesis. Department of Atmospheric Science, Paper No. 234, Colorado State University, Fort Collins, Colorado, pp 1-121

Gray WM (1979) Hurricanes: their formation, structure and likely role in the general circulation. In: Shaw DB (ed) Meteorology over the Tropical Oceans. Royal Meteorological Society, James Glaisher House, Grenville Place, Bracknell, Berks RG, 12 1BX, pp $155-218$

Higaki M, Hayashibara H (2008) Operational storm surge forecasting at Japan Meteorological Agency. http//boramleeffreefr/SSS/ full_papers/2_OSS_Higaki_Masakazupdf

Higaki M, Hayashibara H, Nozaki F (2009) Japan Meteorological Agency Technical Review No 11. http//wwwjmagojp/jma/jmaeng/jma-center/rsmc-hp-pub-eg/techrev/text11pdf

Holland G (1980) An analytical model of the wind and pressure profiles in hurricanes. Mon Wea Rev 108:1212-1218

Holland GJ, Belanger JI, Fritz A (2010) A revised model for radial profiles of hurricane winds. Mon Wea Rev 138:4393-4401. doi:10.1175/2010MWR3317.1 
IMD (1996) Addendum to Storm Atlas from 1971 to 1990. India Meteorological Department, New Delhi, India

International Federation of Red Cross and Red Crescent Societies (2001) Situation report-India Orissa cyclone. Appeal no 28/99, Situation Report 17, Geneva Switzerland

Islam T, Peterson RE (2009) Climatology of landfalling tropical cyclones in Bangladesh 1877-2003. Nat Hazards 48(1): $115-135$

Jain I, Rao AD, Jitendra V, Dube SK (2010) Computation of expected total water levels along the east coast of India. J Coast Res 26(4):681-687

Jelesnianski CP, Chen J, Shaffer WA (1992) SLOSH: sea, lake, and overland surges from hurricanes. Silver Spring, MD, National Weather Service, NOAA TD/NO. 48, pp 1-71

John B, Sinha PC, Dube SK, Mohanty UC, Rao AD (1983) Simulation of storm surges using a three-dimensional numerical model an application to the 1977 Andhra cyclone. Quart J R Met Soc 109:211-224

Jullien S, Marchesiello P, Menkes CE et al (2014) Ocean feedback to tropical cyclones climatology and processes. Clim Dyn 43:2831-2854

Kalsi SR (2006) Orissa super cyclone-A synopsis. Mausam 57(1):1-20

Knaff JA, Harper BA, Brown D et al (2010) Tropical cyclone surface wind structure and wind-pressure relationships. Seventh international workshop on tropical cyclones, pp KN11-KN135

Knapp KR, Kruk MC, Levinson DH, Diamond HJ, Neumann CJ (2010) International Best Track Archive for Climate Stewardship (IBTrACS): unifying tropical cyclone best track data. Bull Am Meteor Soc 91:363-376

Large WG, Pond S (1981) Open ocean momentum flux measurements in moderate to strong winds. J Phys Ocean 11:324-481

Latha G, Rama Rao EP (2007) Surge simulations for 1999 Orissa super cyclone using a finite element model. Nat Hazards 40(3):615-625

Levitus S, Boyer TP (1994) World Ocean atlas 1994, vol 4: temperature. NOAA Atlas, NESDIS, US Department of Commerce, Washington DC, USA, pp 1-117

Levitus S, Burgett R, Boyer TP (1994) World Ocean atlas 1994, vol 3: salinity. NOAA Atlas, NESDIS, US Department of Commerce, Washington DC, USA, pp 1-99

Li Z, Yu W, Li T, Murty VSN, Tangang F (2013) Bimodal character of cyclone climatology in Bay of Bengal modulated by monsoon seasonal cycle. J Clim. doi:10.1175/JCLI-D-11-00627.1

Liang J, Liguang W, Huijun Z (2014) Idealized numerical simulations of tropical cyclone formation associated with monsoon gyres. Adv Atmos Sci 31(2):305-315

Lin I-I, Chen C-H, Pun I-F, Liu WT, Wu C-C (2009) Warm ocean anomaly air sea fuxes and the rapid intensification of tropical cyclone Nargis 2008. Geophys Res Lett 36:L03817. doi:10.1029/ 2008GL035815

Lwin T (1980) Review of methods of storm surge prediction currently used in Burma. Report to the WMO workshop on storm surges, November 10-15, 1980 Rangoon Burma, pp 1-8

MacAfee AW, Pearson GM (2006) Development and testing of tropical cyclone parametric wind models tailored for midlatitude application-preliminary results. J Appl Meteor Climatol 45:1244-1260

Mandal GS, Gupta A (1993) The wind structure, size and damage potential of some recent cyclones of hurricane intensity in the North Indian Ocean. In: Proceedings of the National Symposium TROPMET-93, IMS, March 17-19, 1993, New Delhi, pp 417-427

Mandal M, Mohanty UC, Das AK (2006) Impact of satellite derived wind in mesoscale simulation of Orissa super cyclone. Ind J Mar Sci 35(2):161-173
McBride JL (1995) Tropical cyclone formation. In: Elsberry RL (ed) Global perspectives on tropical cyclones. WMO/TD-No 693, World Meteorological Organization, Geneva, pp 63-105

McPhaden MJ, Foltz GR, Lee T et al (2009) Ocean-atmosphere interactions during cyclone Nargis. Eos Trans 90(7):53-54. doi:10.1029/2009EO070001

Mellor GL (2001) One-dimensional ocean surface layer modeling: a problem and a solution. J Phys Ocean 31:790-809

Mellor GL (2004) Users guide for a three-dimensional primitive equation numerical ocean model. Princeton University Princeton, NJ, 08544-0710, pp 1-56

Mellor GL, Yamada T (1982) Development of a turbulence closure model for geophysical fluid problems. Rev Geophys 20:851-875

Melton G, Gall M, Mitchell JT, Cutter SL (2009) Hurricane Katrina storm surge delineation: implications for future storm surge forecasts and warnings. Nat Hazards 54:519-536

Meng Y, Matsui M, Hibi K (1995) An analytical model for simulation of the wind field in a typhoon boundary layer. J Wind Eng Ind Aerodyn 56:291-310

Miller M (2010) Development of the deterministic system. Forecast products users' meeting, 9-11 June, 2010, ECMWF

Milliff RF, Morzel J, Chelton DB, Freilich MH (2004) Wind stress curl and wind stress divergence biases from rain effects on QSCAT surface wind retrievals. J Atmos Ocean Technol 21(8):1216-1231

Mishra DK, Gupta GR (1976) Estimation of maximum wind speeds in tropical cyclones occurring in the Indian Seas. Indian J Meterol Hydrol Geophys 27(3):285-290

Mohanty UC, Mandal M, Raman S (2004) Simulation of Orissa super cyclone 1999 using PSU/NCAR mesoscale model. Nat Hazards 31:373-390

Mori N, Kato M, Kim S, Mase H, Shibutani Y, Takemi T, Tsuboki K, Yasuda T (2014) Local amplification of storm surge by super typhoon Haiyan in Leyte Gulf. Geophys Res Lett 41(14):5106-5113. doi:10.1002/2014GL060689

Murty TS, Flather RA, Henry RF (1986) The storm surge problem in the Bay of Bengal. Prog Oceanogr 16:195-233

Murty VSN, Subrahmanyam B, Rao LVG, Reddy GV (1998) Seasonal variation of sea surface temperature in the Bay of Bengal during 1992 as derived from NOAA-AVHRR SST data. Int J Remote Sens 19(12):2361-2372

Niedoroda AW, Resio DT, Toro GR, Divoky D, Das HS, Reed CW (2010) Analysis of the coastal Mississippi storm surge hazard. Ocean Eng 37:82-90

Oey L-Y, Ezer T, Lee H-C (2005) Loop current rings and related circulation in the Gulf of Mexico: a review of numerical models and future challenges. In: Sturges W, Fernandez AL (eds) Ocean circulation in the Gulf of Mexico: observations and models. Geophysical Monograph Series, 161, Washington DC, pp 31-56

Oey L-Y, Ezer T, Wang DP, Yin XQ, Fan S-J (2007) Hurricane induced motions and interaction with ocean currents. Cont Shelf Res 27(9):1249-1263. doi:10.1016/j.csr.2007.01.008

Okazaki T, Watabe H, Ishihara T (2005) Development of typhoon simulation technique-toward estimation of typhoon risk in Japan. In: Naprstek J, Fischer C (eds) EACWE4-The fourth European and African conference on wind engineering, 11-15 July, 2005, ITAM AS, Prague, Czech Republic pp 1-366. ISBN: 80862462649788086246260

Paradip Port Trust (1999) The super cyclone of 29-30th October 1999. Chairman's Report, Paradip port, India

Polito PS, Cornilion P (1997) Long baroclinic Rossby waves detected by TOPEX/POSEIDON. J Geophys Res 102:3215-3235

Powell MD, Vickery PJ, Reinhold TA (2003) Reduced drag coefficient for high wind speeds in tropical cyclones. Nature 422:279-283. doi:10.1038/nature01481 
Prasad TG, Hogan PJ (2007) Upper-ocean response to Hurricane Ivan in a 1/25 degrees nested Gulf of Mexico HYCOM. J Geophys Res 112:C04013. doi:10.1029/2006JC003695

Probst P, Franchello G (2012) Global storm surge forecast and inundation modeling. JRC: Scientific Technical Report 68133, EUR 25233 EN, European Commission, pp 1-48. ISSN:18319424. doi:10.2788/14951

Rankine WJM (1982) A manual of applied physics, 10th edn. Charles Griffs and Company, London, pp 1-663

Rao AD, Dube SK, Chittibabu P, Sinha PC (1993) Numerical simulations of Storm surges and associated currents around Indian Peninsula. In: Proceedings of the National Symposium TROPMET-93, IMS, March 17-19 1993, New Delhi, pp 127-136

Rao AD, Murty PLN, Jain I, Kankara RS, Dube SK, Murty TS (2012) Simulation of water levels and extent of coastal inundation due to a cyclonic storm along the east coast of India. Nat Hazards. doi:10.1007/s11069-012-0193-6

Rego JL, Li C (2010) Storm surge propagation in Galveston Bay during hurricane Ike. J Mar Syst 82:265-279

Riehl H (1979) Climate and weather in the tropics. Academic Press, New York, p 394

Sadhuram Y, Rao BP, Rao DP, Shastri PNM, Subrahmanyam MV (2004) Seasonal variability of cyclone heat potential in the Bay of Bengal. Nat Hazards 32:191-209. doi:10.1023/B:NHAZ. 0000031313.43492.a8

Saheb P, Arun C, Pandey PC, Basu S, Satsangi SK, Ravichndran M (2009) Numerical simulation of Bay of Bengal circulation features from Ocean General Circulation model. Mar Geodesy 32(1): $1-18$

Saito K, Fujita T, Yamada Y et al (2006) The operational JMA nonhydrostatic mesoscale model. Mon Wea Rev 134(4): 1266-1298

Schenkel BA, Hart RE (2012) An examination of tropical cyclone position intensity and intensity life cycle within atmospheric reanalysis datasets. J Clim 25:3453-3475

Sengupta D, Goddalehundi BR, Anitha D (2008) Cyclone-induced mixing does not cool SST in the post-monsoon North Bay of Bengal. Atmos Sci Lett 9(1):1-6

Shaji C, Kar SC, Vishal T (2014) Storm Surge studies in the North Indian Ocean: a review. Indian J Geo-Mar Sci 42(2):125-147

Shetye SR, Gouveia AD, Shenoi SC et al (1993) The western boundary current of the seasonal subtropical gyre in the Bay of Bengal. J Geophys Res 98(C1):945-954

Shetye SR, Gouveia AD, Shankar D et al (1996) Hydrography and circulation in the western Bay of Bengal during the northeast monsoon. J Geophys Res 101:14011-14025

Sil S, Chakraborty A (2011) Numerical simulation of seasonal variations in circulations of the Bay of Bengal. J Ocean Mar Sci 25:127-135

Sinha PC, Jain I, Bhardwaj N, Rao AD, Dube SK (2008) Numerical modeling of tide-surge interaction along Orissa coast of India. Nat Hazards 45:413-427

Smagorinski J (1963) General circulation experiments with the primitive equations I. The basic experiment. Mon Wea Rev 91(3):99-164

Spentza E, Chicaud B, Andoin IG de (2012) Parametric modeling of cyclonic winds for quick location assessment. In: Proceedings of the annual international offshore and polar engineering conference. International society of offshore and polar engineers (ISOPE), Rhodes, Greece, June 17-23, 2012, pp 770-777

Sprintall J, Tomczak M (1992) Evidence of the barrier layer in the surface layer of the tropics. J Geophys Res 97(C5):7305-7316

Stan C (2012) Is cumulus convection the concertmaster of tropical cyclone activity in the Atlantic? Geophys Res Lett 39(19): L19716. doi:10.1029/2012GL053449
Stenger RA, Elsberry RL (2014) Outer vortex wind structure changes during and following tropical cyclone secondary eyewall formation. Trop Cyclone Res Rev 2:196-206

Sumesh KG, Rameshkumar MR (2013) Tropical cyclones over north Indian Ocean during El-Niño Modoki years. Nat Hazards 68(2): 1057-1074

Swiss Re (2002) Natural catastrophes and man-made disasters in 2001: Manmade losses take on a new dimension. Sigma 1/2002, Swiss Reinsurance Company, Zurich, pp 1-25

Veneziano JM (1998) Response of South China Sea to forcing by tropical cyclone Ernie 1996. PhD Dissertation, Naval Post Graduate School, Monterey California, p 193

Vickery PJ, Masters FJ, Powell MD, Wadhera D (2009) Hurricane hazard modeling: the past present and future. J Wind Eng Ind Aerodyn 97(7-8):392-405. doi:10.1016/j.jweia.2009.05.005

Vinayachandran PN, Shetye SR, Sengupta D, Gadgil S (1996) Forcing mechanisms of the Bay of Bengal circulation. Curr Sci 71(10): 753-763

Wang J-W, Han W (2014) The Bay of Bengal upper-ocean response to tropical cyclone forcing during 1999. J Geophys Res (Oceans) 119:98-120. doi:10.1002/2013JC008965

Wang J-W, Han W, Sriver RL (2012) Impact of tropical cyclones on the ocean heat budget in the Bay of Bengal during 1999, part II: processes and interpretations. J Geophys Res (Oceans) 117:C09021. doi:10.1029/2012JC008373

Wang S-Y, Buckley BM, Yoon JH, Fosu BO (2013) Intensification of premonsoon tropical cyclones in the Bay of Bengal and its impacts on Myanmar. J Geophys Res (Atmos) 118:4373-4384. doi: $10.1002 /$ jgrd. 50396

Webster PJ (2008) Myanmar's deadly daodil. Nat Geosci 1(8): 488-490

Willoughby HE, Darling RWR, Rahn ME (2006) Parametric representation of the primary Hurricane vortex part II: A new family of sectionally continuous profiles. Mon Wea Rev 134:1102-1120

WMO (2010) The WMO/ICSU seventh international workshop on tropical cyclones (IWTC-VII). 15-20 November, 2010, La Réunion France, WWRP (2011)-1, TD/No 1561, World Meteorological Organization, Geneva

Wood VT, White LW (2011) A new parametric model of vortex tangential-wind profiles: development testing and verification. J Atmos Sci 68:990-1006

Wunsch C, Stammer D (1998) Satellite altimetery, the marine geoid and the oceanic general circulation. Ann Rev Earth Planet Sci 26:219-254

Xia M, Xia L, Pietrafesa LJ, Peng M (2008) A numerical study of storm surge in the Cape Fear river estuary and adjacent coast. J Coast Res 24:159-167

IMD India Meteorological Department. http://www.imd.gov.in

JTWC Joint Typhoon Warning Centre. Annual tropical cyclone report. http//wwwnpmocnavymil/jtwc/atcr

Unisys Weather Information Services. http://www.weather.unisys. com

Yanase W, Taniguchi H, Satoh M (2010) The genesis of tropical cyclone Nargis (2008): Environmental modulation and numerical predictability. J Meteor Soc Jpn 88(3):497-519

Yanase W, Satoh M, Taniguchi H, Fujinami H (2012) Seasonal and intra-seasonal modulation of tropical cyclogenesis environment over the Bay of Bengal during the extended summer. J Clim 25:2914-2930

Yang H, Liu Q, Liu Z, Wang D, Liu X (2002) A general circulation model study of the dynamics of the upper ocean circulation of the South China Sea. J Geophys Res 107(C7):3085. doi:10.1029/ 2001JC001084

Yin X, Wang Z, Liu Y, Yi Xu (2007) Ocean response to Typhoon Ketsana traveling over the northwest Pacific and a numerical 
model approach. Geophys Res Lett 34(21):L21606. doi:10.1029/ 2007GL031477

You SH, Lee W-J, Moon KS (2010) Comparison of storm surge/ tide predictions between a 2-D operational forecast system the regional tide/storm surge model (RTSM) and the 3-D regional ocean modeling system (ROMS). Ocean Dyn 60(2):443-459 